\title{
Extracting Road Traffic Volume in the City before and during covid-19 through Video Remote Sensing
}

\author{
Elżbieta Macioszek *(D) and Agata Kurek
}

Department of Transport Systems, Traffic Engineering and Logistics, Faculty of Transport and Aviation Engineering, Silesian University of Technology, Krasińskiego 8 Street, 40-019 Katowice, Poland; agata.kurek@polsl.pl

* Correspondence: elzbieta.macioszek@polsl.pl; Tel.: +48-32-603-41-50

check for updates

Citation: Macioszek, E.; Kurek, A. Extracting Road Traffic Volume in the City before and during covid-19 through Video Remote Sensing. Remote Sens. 2021, 13, 2329. https:// doi.org/10.3390/rs13122329

Academic Editors: Biswajeet Pradhan and Chengbin Deng

Received: 8 April 2021

Accepted: 11 June 2021

Published: 14 June 2021

Publisher's Note: MDPI stays neutral with regard to jurisdictional claims in published maps and institutional affiliations.

Copyright: (c) 2021 by the authors. Licensee MDPI, Basel, Switzerland. This article is an open access article distributed under the terms and conditions of the Creative Commons Attribution (CC BY) license (https:// creativecommons.org/licenses/by/ $4.0 /)$.

\begin{abstract}
Continuous, automatic measurements of road traffic volume allow the obtaining of information on daily, weekly or seasonal fluctuations in road traffic volume. They are the basis for calculating the annual average daily traffic volume, obtaining information about the relevant traffic volume, or calculating indicators for converting traffic volume from short-term measurements to average daily traffic volume. The covid-19 pandemic has contributed to extensive social and economic anomalies worldwide. In addition to the health consequences, the impact on travel behavior on the transport network was also sudden, extensive, and unpredictable. Changes in the transport behavior resulted in different values of traffic volume on the road and street network than before. The article presents road traffic volume analysis in the city before and during the restrictions related to covid-19. Selected traffic characteristics were compared for 2019 and 2020. This analysis made it possible to characterize the daily, weekly and annual variability of traffic volume in 2019 and 2020. Moreover, the article attempts to estimate daily traffic patterns at particular stages of the pandemic. These types of patterns were also constructed for the weeks in 2019 corresponding to these stages of the pandemic. Daily traffic volume distributions in 2020 were compared with the corresponding ones in 2019. The obtained results may be useful in terms of planning operational and strategic activities in the field of traffic management in the city and management in subsequent stages of a pandemic or subsequent pandemics.
\end{abstract}

Keywords: road traffic volume; traffic flow parameters; video detection; remote sensing data collecting; covid-19 time

\section{Introduction}

The Highway Capacity Manual [1] usually distinguishes between volume and flow rate to measure the number of vehicles passing over a given point or section of a lane during a given time interval. Volume is the number of vehicles that pass a point for one hour [1-4]. Flow rate denotes the number of vehicles that pass a point through a time interval of less than $1 \mathrm{~h}$ (usually $15 \mathrm{~min}$ ) but expressed as an equivalent hourly rate. Another relevant reference unit for road traffic analysis is the day or the average daily traffic, which is the ratio between the total volume and the duration (in days) of the analysis.

Cyclicality and periodicity should be taken into account when planning the dates and duration of traffic evaluation and analysis. Traffic research should be conducted on average working days such as Tuesday, Wednesday, and Thursday and average months such as March, May, June, September, and October. This selection of measuring periods makes it possible to avoid the traffic peaks corresponding to weekends and holidays.

It can also cover different periods, e.g., $1 \mathrm{~h}, 4 \mathrm{~h}, 12 \mathrm{~h}, 16 \mathrm{~h}$, etc. Traffic volume measurement can take place at both nodes (e.g., intersections) and network base at a different scale (e.g., area, city, region). The smaller the area, the more important it is to measure variability over the day. Traffic measurements and studies are useful to examine temporal and spatial variability, the traffic split along with the two directions, and the 
generic structure of traffic. They are also useful for designing infrastructure as well as regulation strategies. The systematic observation of traffic volume over the years has identified cyclicity patterns under certain conditions. They allowed for some forms of transferability of the results in time and space.

Traffic volume measurements can be carried out by various methods [5-10]:

- manual measurement methods: this is the simplest and most common method that consists of registering each participant of the traffic passing the road section per unit time by using manual recording on forms or mechanical or electronic tools,

- automatic measurement methods: consisting of automatic recognition and registration of passing participants of the traffic by using counters activated by detection loops, photoelectric sensors, radar sensors, and video detection. Video detection is widely used in field research. Modern traffic monitoring systems are often part of the areabased Intelligent Transport Systems (ITS). They can also classify vehicles and collect information about the speed of vehicles and the time gaps between them.

Major roads in many developed countries are now equipped with automated traffic counters, tolling systems, and other technologies. These technologies can deliver regular and reliable data on daily road traffic volume. The availability of such data for secondary and tertiary routes is limited in most countries [11-17].

The covid-19 pandemic changed the lives of almost all people around the world. Cases of infection with the SARS-CoV-2 virus were also recorded in Poland from 4 March 2020. A timeline (Figure 1) presents the chronology of the implementation of legal regulations in Poland in connection with the increase in the number of SARS-CoV-2 infections in 2020. On the first days of week 11 of 2020 (i.e., from 12 to 15 March), restrictions were introduced, such as: suspension of stationary classes in nurseries, kindergartens, children's clubs, schools, and public and private educational institutions (12 March); closing of restaurants, bars, cinemas, theaters, museums, art galleries, libraries, gyms, fitness clubs, hotels, shops in shopping centers, excluding grocery stores, pharmacies, drugstores and laundries (14 March); and closing borders to foreigners (15 March).

In Poland, the state of epidemic emergency was declared in the 12th week of 2020 (20 March), which was also the first full week of lockdown. The number of people in public transport vehicles was reduced to half the number of seats in the 13th week of 2020, to prevent the spread of the SARS-CoV-2 virus. Further restrictions were introduced, i.e., closure of hairdressing and beauty salons, rehabilitation centers, independent health care facilities, and hotels in the 14th week of 2020, due to the worsening epidemic situation in the country. No possibility of organizing mass cultural, sports, entertainment, and recreational events, being on beaches and green areas, and using bike-sharing systems was introduced on 1 April. A total lockdown was enforced in the country in the following weeks. Forest access and recreation permits were issued in the 17th week of 2020. From the 19th week of 2020, hotels, libraries, museums, and art galleries (4 May) and cinemas, theaters, gyms, and fitness clubs (6 May) reopened. Borders (13 May) were opened in the 20th week of 2020. Shopping centers, hairdressing and beauty salons, bars, and restaurants were reopened in the 21st week of 2020. Moreover, the number of passengers in public transport vehicles was increased to $30 \%$ of all seats (18 May). Hotels opened in the 22 nd week of 2020 . The summer vacation period came in Poland from the 23rd to the 32nd week of 2020. The yellow zone for the analyzed area was introduced in the 32nd week of 2020. The beginning of the autumn period and colder days contributed to a rapid increase in the number of SARS-CoV-2 virus infections. This period was called the second wave of the epidemic. The entire country was included in the red zone (24 October) in the 43rd week of 2020. The functioning of many business entities, services, schools, and activities were suspended due to the introduction of a red zone for the entire country. Classes in university, secondary schools, and grades 4-8 in primary schools were conducted only in remote mode from the 43rd week of 2020. Additionally, activities were closed such as swimming pools, gyms, fitness clubs, sports events without public spectators, sanatoriums, and restaurants, and passengers in public transport vehicles were reduced to $50 \%$ of seats or $30 \%$ of all places 
(sitting and standing). In the 44th week of 2020, cemeteries were closed (30 October) because of the celebration of All Saints' Day on 1 November, which usually gathers many people in cemeteries.
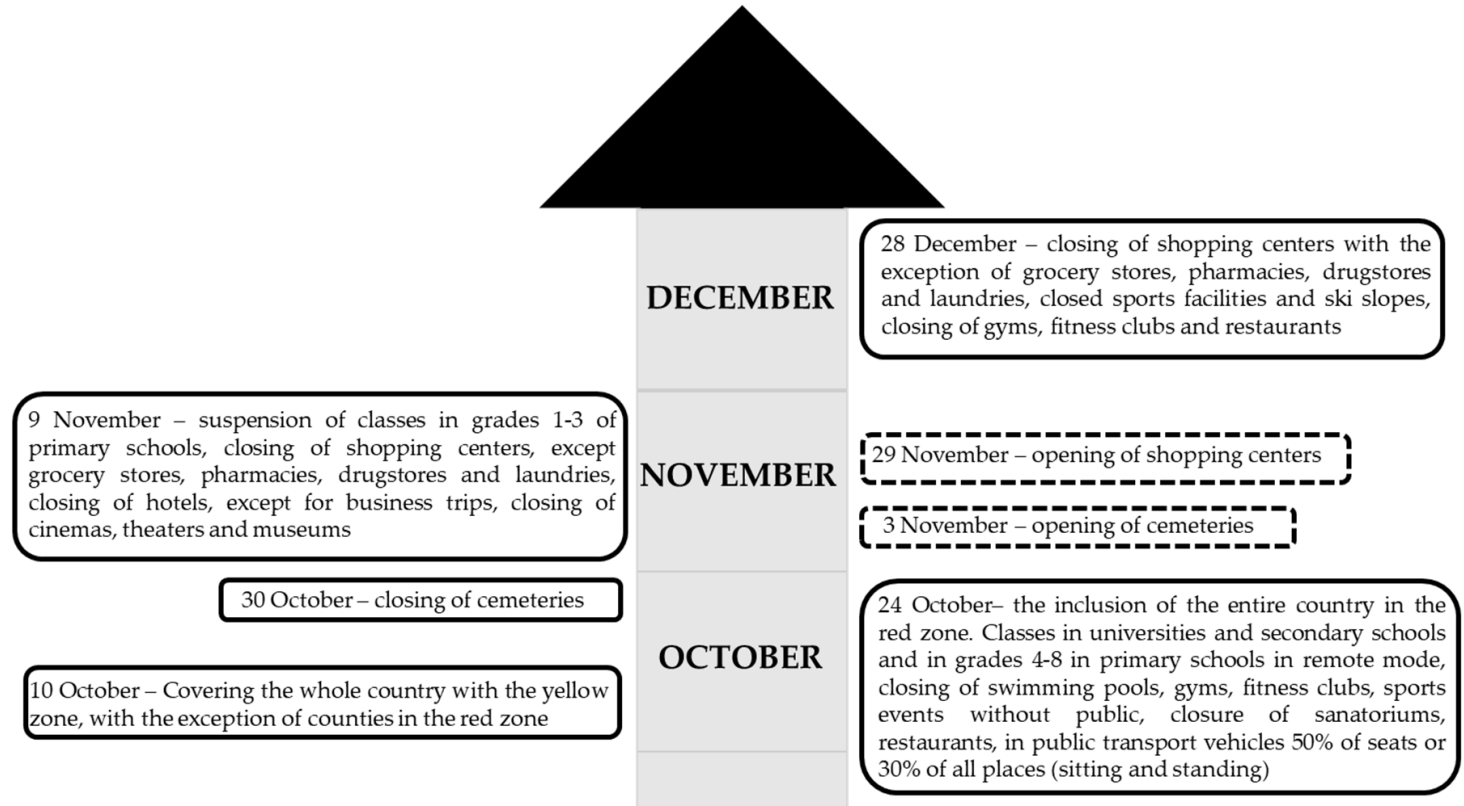

SEPTEMBER

8 August - division of counties in Poland into the yellow and red zones.

In the yellow zone, limiting the number of people in restaurants, amusement parks, sports events, cultural fairs, congresses.

In the red zone, in public transport vehicles $50 \%$ of seats or $30 \%$ of all places (sitting and standing), no amusement parks, sanatoriums, restrictions on the number of people restaurants, no participation of the public in sports events

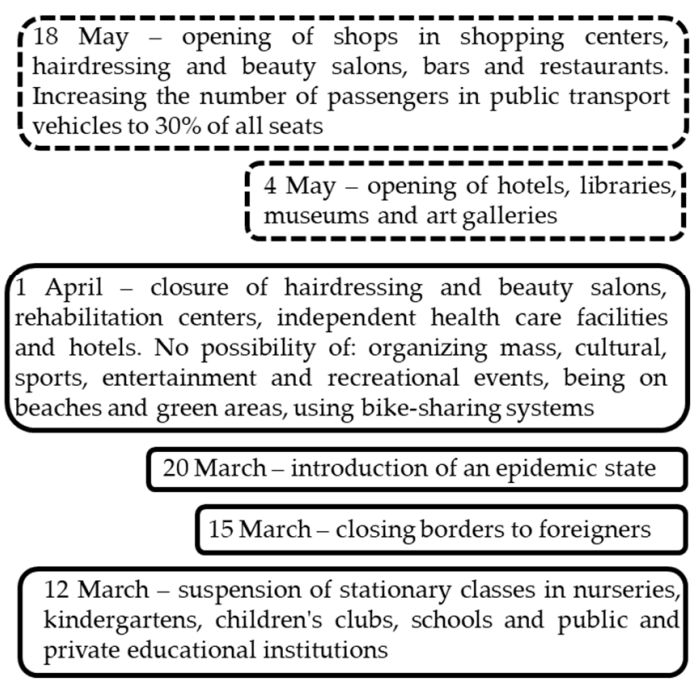

\section{AUGUST}

JULY

JUNE

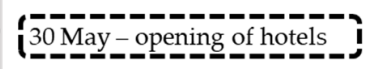

MAY

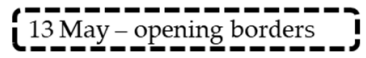

6 May -opening of cinemas, theaters, gyms and fitness clubs

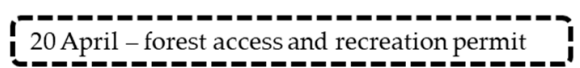

APRIL

24 March - reducing the number of people in public
transport vehicles to half the number of seats

14 March - closing of restaurants, bars, cinemas, theaters, museums, art galleries, libraries, gyms, fitness clubs, hotels, shops in shopping centers, excluding grocery stores, pharmacies, drugstores and laundries

Figure 1. Timeline for legal regulations introduced in Poland in 2020 due to the increase in the number of SARS-CoV-2 virus infections [18-26]. Solid line indicates the introduction of the selected restrictions, and the dashed line means the withdrawal of the selected restrictions. 
In the 45th week of 2020, cemeteries were open (3 November). Classes in grades 1-3 of primary schools were suspended due to the increasing number of SARS-CoV-2 virus infections. Activities were suspended, such as: shopping centers (except grocery stores, pharmacies, drugstores, and laundries), hotels (except for business trips), cinemas, theaters, and museums in the 46th week of 2020. Shopping centers (29 November) were reopened in the 48th week of 2020, in connection with the approaching Christmas season. After Christmas (53rd week of 2020) such activities were closed as: shopping centers (except for grocery stores, pharmacies, drugstores, and laundries), sports facilities and ski slopes, gyms, fitness clubs, and restaurants.

So far, research works in the area of monitoring changes caused by covid-19 in the characteristics of road traffic flows have also been published. The covid-19 pandemic has significantly influenced almost every aspect of daily life, including traffic flow parameters. Thus, it is important to measure the impact of covid-19 on traffic flow parameters to properly respond to changes in traffic patterns. Initially, the published works concerned changes in the characteristics of traffic flow in the city of Wuhan in China and modeling the relationship between outbound traffic from Wuhan and coronavirus disease incidences (e.g., [27]). In addition, works were related to the capability of SAR StripMap imaging mode data to monitoring traffic volume on the bridges crossing the Yangtze river in Wuhan [28]. These works related to the analysis of road traffic characteristics in various places around the world affected by covid-19, e.g., USA (e.g., [29,30]) andItaly (e.g., [31]). The research also covered travel behavior before and during restrictions related to covid-19 in the USA [32]. However, so far, no studies have been published that analyzed the traffic flow characteristics in Polish cities before and during different stages of restrictions related to covid-19, according to the authors' knowledge. Hence, there is a need to identify and systematize this type of change in Polish conditions. Therefore, the aim of the article is road traffic volume analysis in the selected city located in Poland before and during restrictions related to covid-19. The research questions are as follows: how have road traffic volume values changed in the selected intersections in the city before and during the restrictions related to covid-19? What are the differences between daily traffic volume distributions on the selected intersections in the city in 2020 and in 2019?

The article consists of seven sections. After the introduction section, the materials and methods are described, which are used in the analysis. In the next section, the characteristics of daily, weekly, and annual variability of traffic volume in 2019 and 2020 in Gliwice (Poland) are presented. After that, an attempt is made to estimate daily traffic patterns at particular stages of the covid-19 pandemic. These types of patterns are also constructed for the weeks in 2019 corresponding to these stages of the pandemic. The last two sections contain a discussion on the obtained results and formulated conclusions.

\section{Materials and Methods}

The main purpose of the study was road traffic volume analysis in the city before and during restrictions related to covid-19. Data were obtained on traffic volume for the analysis of road traffic volume distribution on selected intersections in 2019 and 2020 from the Traffic Control Center (TCC) in Gliwice. The data included each day in 2019 and 2020 divided into 15-min intervals, taking into account the direction and structure of traffic, along with the accuracy of the traffic lane.

To characterize changes in the traffic volume values before and during restrictions related to covid-19 for selected intersections, the following traffic characteristics were compared for 2019 and 2020:

- average traffic volume on working days in particular weeks of the year,

- the total traffic volume on particular days of the week in particular months,

- the distribution of total traffic volume on working days in particular weeks and the forecast traffic volume for 2020,

- the distribution of total traffic volume in particular weeks and the forecast of traffic volume for 2020, 
- road traffic variability factors in the following weeks of the year,

- road traffic variability factors for annual average daily traffic volume,

- the daily road traffic volume distribution in particular weeks.

Firstly, 24-h data from Monday to Friday in particular weeks were used for the average traffic volume on working days in particular weeks of the year analysis. In further analysis, public holidays and days before and after public holidays were not taken into account in the values of the average traffic volume in particular weeks.

Eight signalized intersections located in the city of Gliwice were selected for further analysis: (1) Andersa-Okulickiego; (2) Kozielska-Okulickiego; (3) Orlickiego-PortowaŚliwki; (4) Orlickiego-Wyspiańskiego; (5) Pszczyńska-Pocztowa; (6) Chorzowska-Knurowska; (7) Chorzowska-Zabrska and (8) Nowy Świat-Pszczyńska-Mikołowska (Figure 2). All intersections are located on important roads, which leading and discharging traffic flows to and from the city center. These intersections are also important communication junctions in the city transport system, serving significant traffic volume each day.

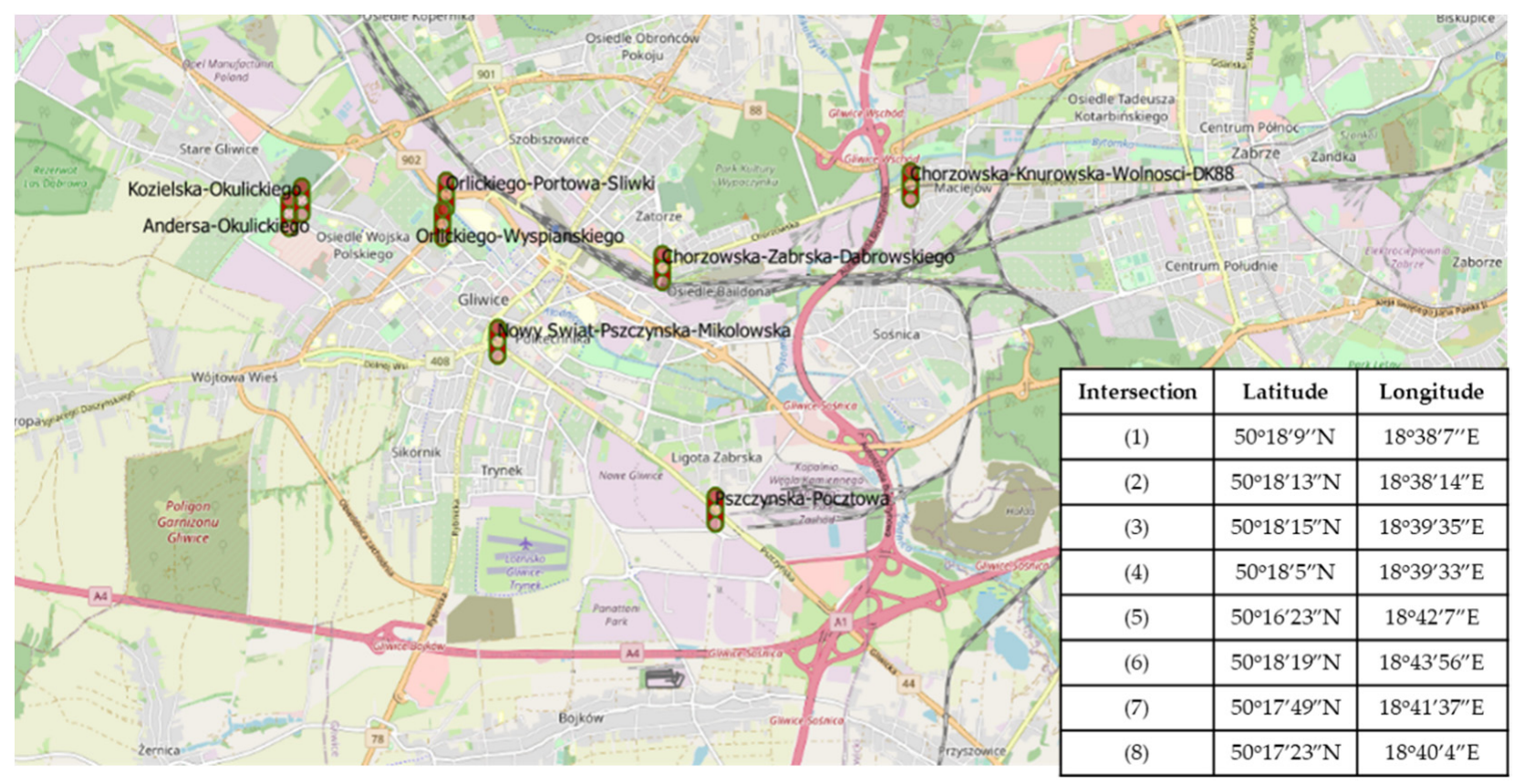

Figure 2. Localization of analyzed intersections in the background of the city of Gliwice. Source: Own research based on Open Street Map [33].

The above-mentioned intersections are equipped with vehicle detection and traffic control systems, video detection cameras, and induction loops, which are part of the Intelligent Transport System in the city of Gliwice (ITS Gliwice). Figure 3 presents schemes of the analyzed intersections along with views from selected vehicle video detection systems at the analyzed intersections. Table 1 presents the indication of the week's number in 2019 and 2020 used in further analysis. Some weeks of the year began in one month and ended the next. 
(a)

Latitude: $50^{\circ} 18^{\prime} 9^{\prime \prime} \mathrm{N}$

Longitude: $18^{\circ} 38^{\prime} 7^{\prime \prime} \mathrm{E}$

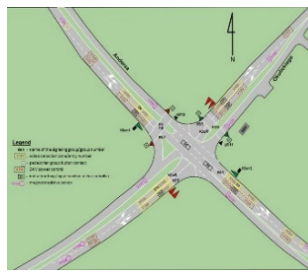

(e)

Latitude: $50^{\circ} 18^{\prime} 15^{\prime \prime} \mathrm{N}$

Longitude: $18^{\circ} 39^{\prime} 35^{\prime \prime} \mathrm{E}$

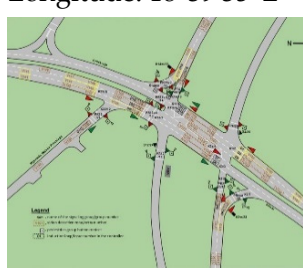

(i)

Latitude: $50^{\circ} 16^{\prime} 23^{\prime \prime} \mathrm{N}$

Longitude: $18^{\circ} 42^{\prime} 7 " \mathrm{E}$

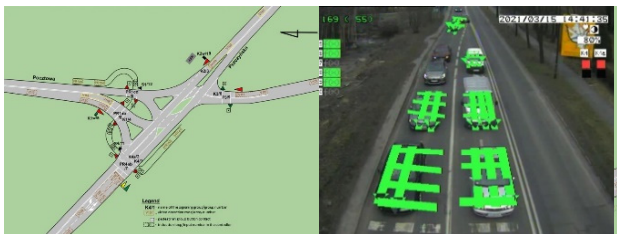

(m)

Latitude: $50^{\circ} 17^{\prime} 49^{\prime \prime} \mathrm{N}$

Longitude: $18^{\circ} 41^{\prime} 37^{\prime \prime} \mathrm{E}$

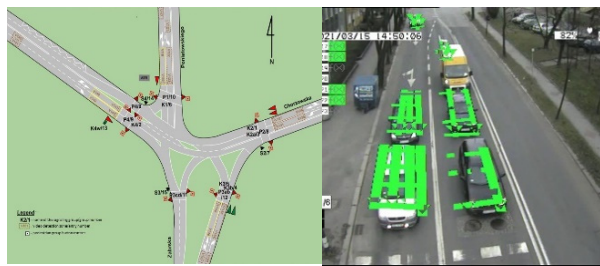

(c)

Latitude: $50^{\circ} 18^{\prime} 13^{\prime \prime} \mathrm{N}$

Longitude: $18^{\circ} 38^{\prime} 14^{\prime \prime} \mathrm{E}$ (d)

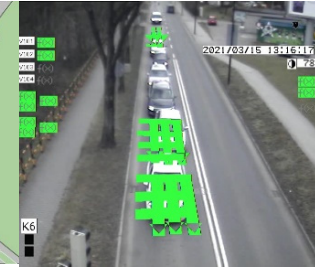

(h)

Latitude: $50^{\circ} 18^{\prime} 5^{\prime \prime} \mathrm{N}$

Longitude: $18^{\circ} 39^{\prime} 33^{\prime \prime} \mathrm{E}$

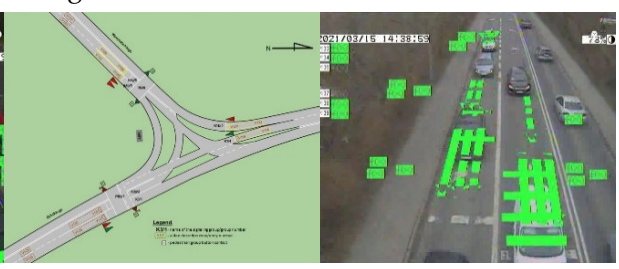

(k)

Latitude: $50^{\circ} 18^{\prime} 19^{\prime \prime} \mathrm{N}$

Longitude: $18^{\circ} 43^{\prime} 56^{\prime \prime} \mathrm{E}$

(l)

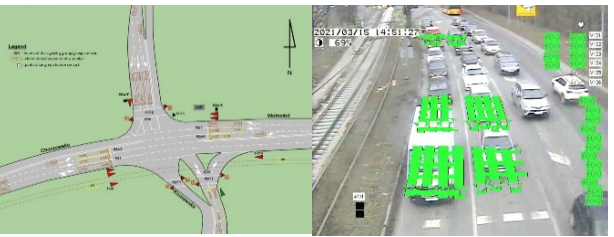

(p)

Latitude: $50^{\circ} 17^{\prime} 23^{\prime \prime} \mathrm{N}$

Longitude: $18^{\circ} 40^{\prime} 4^{\prime \prime} \mathrm{E}$

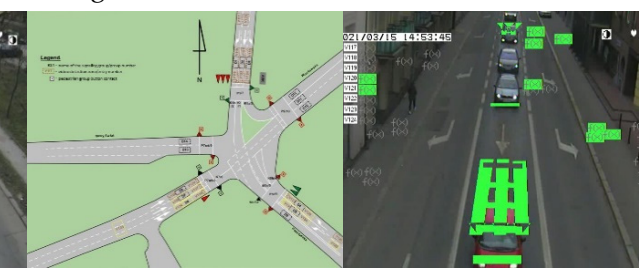

Figure 3. Analyzed intersections in Gliwice (a). scheme of intersection with marked locations of video detection zones at the inlets of Andersa-Okulickiego intersection; (b). view from selected traffic monitoring camera on Andersa-Okulickiego intersection; (c) scheme of intersection with marked locations of video detection zones at the inlets of Kozielska-Okulickiego intersection; (d) view from selected traffic monitoring camera on Kozielska-Okulickiego intersection; (e) scheme of intersection with marked locations of video detection zones at the inlets of Orlickiego-Portowa-Śliwki intersection; (f) view from selected traffic monitoring camera on Orlickiego-Portowa-Śliwki intersection; (g) scheme of intersection with marked locations of video detection zones at the inlets of Orlickiego-Wyspiańskiego intersection; (h) view from selected traffic monitoring camera on Orlickiego-Wyspiańskiego intersection; (i) scheme of intersection with marked locations of video detection zones at the inlets of Pszczyńska-Pocztowa intersection; (j) view from selected traffic monitoring camera on PszczyńskaPocztowa intersection; (k) scheme of intersection with marked locations of video detection zones at the inlets of Chorzowska-Knurowska intersection; (1) view from selected traffic monitoring camera on Chorzowska-Knurowska intersection; (m) scheme of intersection with marked locations of video detection zones at the inlets of Chorzowska-Zabrska intersection; (n) view from selected traffic monitoring camera on Chorzowska-Zabrska intersection; (o) scheme of intersection with marked locations of video detection zones at the inlets of Nowy Świat-Pszczyńska-Mikołowska intersection; (p) view from selected traffic monitoring camera on Nowy Świat-Pszczyńska-Mikołowska intersection. 
Table 1. The week's numbers in 2019 and 2020.

\begin{tabular}{ccc}
\hline \multirow{2}{*}{ Month } & \multicolumn{2}{c}{ Week Numbers } \\
\cline { 2 - 3 } & $\mathbf{2 0 1 9}$ & $\mathbf{2 0 2 0}$ \\
\hline February & $7,8,9$ & $7,8,9$ \\
March & $9,10,11,12,13$ & $9,10,11,12,13,14$ \\
April & $14,15,16,17,18$ & $14,15,16,17,18$ \\
May & $18,19,20,21,22$ & $18,19,20,21,22$ \\
June & $22,23,24,25,26$ & $23,24,25,26,27$ \\
July & $27,28,29,30,31$ & $27,28,29,30,31$ \\
August & $31,32,33,34,35$ & $31,32,33,34,35,36$ \\
September & $35,36,37,38,39,40$ & $36,37,38,39,40$ \\
October & $40,41,42,43,44$ & $40,41,42,43,44$ \\
November & $44,45,46,47,48$ & $44,45,46,47,48,49$ \\
December & $48,49,50,51$ & $49,50,51$ \\
\hline
\end{tabular}

In the analyzed period, there were missing data on hourly traffic volume for 795 days (423 in 2019 and 372 in 2020) taking into account all analyzed intersections. Tables 2 and 3 present the number of days with missing or defective data in the particular months of 2019 and 2020. These missing data were caused by system failure, induction loop failure, lack or interruption of power supply or inability to create a telecommunications connection (modem connection) with the intersection controller, or weather conditions unfavorable for the functioning of the system (heavy rainfall, snowfall, strong sunlight, etc.). Missing data on the traffic volume of up to one hour a day were supplemented (i.e., determined as average values from data from the neighboring hours). This assumption is a simplification, but using data from neighboring hours or hours from previous days allows for the elimination of gross errors from the data. Days with such supplemented data were treated as days with complete data. Missing data for more than one hour in a day was considered as a lack of data for the entire day. There were also cases where the system failed and recorded unrealistically low or high traffic volume (compared to hours and days on other days). Such cases were found to be defective and were excluded from the analysis. These days constitue from $12.88 \%$ to $16.16 \%$ of days in 2019 and from $8.74 \%$ to $15.85 \%$ of days in 2020 .

Table 2. The number of days with missing or defective data in 2019.

\begin{tabular}{|c|c|c|c|c|c|c|c|c|c|c|c|c|c|c|}
\hline Intersection & I & II & III & IV & $\mathbf{V}$ & VI & VII & VIII & IX & $X$ & XI & XII & $\begin{array}{c}\text { Total } \\
\text { in } 2019 \\
\text { [days] }\end{array}$ & $\begin{array}{c}\text { Data } \\
\text { Completeness } \\
{[\%]}\end{array}$ \\
\hline (1) & 31 & 1 & 1 & 2 & 1 & 4 & 1 & 3 & 1 & 1 & 1 & 1 & 48 & 13.15 \\
\hline (2) & 31 & 4 & 0 & 2 & 3 & 1 & 3 & 2 & 2 & 1 & 2 & 8 & 59 & 16.16 \\
\hline (3) & 31 & 3 & 5 & 1 & 2 & 1 & 0 & 2 & 1 & 4 & 3 & 2 & 55 & 15.07 \\
\hline (4) & 31 & 6 & 1 & 1 & 0 & 3 & 1 & 2 & 1 & 3 & 6 & 3 & 58 & 15.89 \\
\hline (5) & 31 & 2 & 0 & 3 & 2 & 0 & 0 & 1 & 4 & 2 & 2 & 1 & 48 & 13.15 \\
\hline (6) & 31 & 5 & 2 & 1 & 3 & 2 & 1 & 4 & 2 & 1 & 1 & 1 & 54 & 14.79 \\
\hline (7) & 31 & 0 & 2 & 1 & 3 & 4 & 2 & 0 & 1 & 0 & 2 & 1 & 47 & 12.88 \\
\hline (8) & 31 & 2 & 3 & 2 & 4 & 4 & 3 & 1 & 1 & 0 & 1 & 2 & 54 & 14.79 \\
\hline
\end{tabular}


Table 3. The number of days with missing or defective data in 2020.

\begin{tabular}{|c|c|c|c|c|c|c|c|c|c|c|c|c|c|c|}
\hline Intersection & $\mathbf{I}$ & II & III & IV & V & VI & VII & VIII & IX & $X$ & XI & XII & $\begin{array}{c}\text { Total } \\
\text { in } 2020 \\
\text { [days] }\end{array}$ & $\begin{array}{c}\text { Data } \\
\text { Completeness } \\
{[\%]} \\
\end{array}$ \\
\hline (1) & 2 & 1 & 14 & 4 & 2 & 7 & 10 & 5 & 4 & 6 & 2 & 1 & 58 & 15.85 \\
\hline (2) & 3 & 0 & 2 & 8 & 7 & 4 & 3 & 6 & 2 & 1 & 7 & 2 & 45 & 12.30 \\
\hline (3) & 4 & 6 & 2 & 2 & 1 & 2 & 7 & 8 & 3 & 2 & 0 & 5 & 42 & 11.48 \\
\hline (4) & 21 & 2 & 0 & 1 & 2 & 3 & 2 & 8 & 7 & 3 & 7 & 0 & 56 & 15.30 \\
\hline (5) & 16 & 2 & 1 & 0 & 3 & 9 & 3 & 4 & 3 & 1 & 4 & 2 & 48 & 13.11 \\
\hline (6) & 2 & 1 & 3 & 2 & 1 & 2 & 1 & 9 & 4 & 1 & 0 & 6 & 32 & 8.74 \\
\hline (7) & 4 & 7 & 2 & 1 & 1 & 0 & 6 & 8 & 4 & 3 & 1 & 1 & 38 & 10.38 \\
\hline (8) & 11 & 2 & 2 & 7 & 4 & 3 & 2 & 6 & 2 & 2 & 3 & 9 & 53 & 14.48 \\
\hline
\end{tabular}

The missing data were supplemented based on the conclusions from the literature [34-36]. The detected missing data was corrected using a weighted moving average method. The value of the predicted variable is determined as the weighted average of the last $k$ real implementations of this variable, i.e., the last $k$ elements of the time series [37]:

$$
y_{t}^{F}=\sum_{i=1}^{k} w_{i} \cdot y_{i+(n-k)}
$$

where:

$y_{t}^{F}$-forecast of the variable $Y$ determined for the moment or period $t$,

$y_{t}$ - the value of the variable $Y$ as per moment or period $t$,

$k$-smoothing constant,

$w$-weight assigned to observations,

$n$-number of time series elements of the predicted variable $Y$.

Positive weight values were adopted due to the aging of the data. Weights should sum up to one and fulfill the conditions according to the assumptions [37]:

$$
\sum_{i=1}^{k} w_{i}=1,0<w_{i} \leq 1
$$

Appropriate values of particular weights were selected iteratively based on minimizing the mean square error of the forecast [38]:

$$
M S E=\frac{1}{n-k} \sum_{t=k+1}^{n}\left(y_{t}-y_{t}^{F}\right)^{2} \rightarrow \min
$$

The characteristics and features of road traffic were tested with the use of digital cameras. This method is classified as a passive remote sensing tool. Research with the use of digital cameras is characterized by very high measurement accuracy [39,40]. Moreover, this method is often used for the spatial-temporal analysis of traffic patterns [41] or road traffic density estimation [42]. It is often used for data collection in road traffic analyses due to its advantages $[43,44]$.

\section{Characteristics of Weekly and Annual Variability of Traffic Volume in 2019 and 2020}

In the first stage of the work, the total traffic volume at the analyzed intersections on particular days of the week, in particular months in 2019 and 2020, and AADT in 2019 and 2020, was analyzed (Figure 4). In Figure 4, the solid line marks the data from 2019, while the dashed line marks the data from 2020. On working days (from Monday to Friday) the values of traffic volume are at a similar level in all months of 2019 and 2020, with slight fluctuations on particular days of the week. On weekend days (Saturday and Sunday) there is a significant decrease in traffic volume compared to the values recorded on working days. 
The obtained results confirm the correctness of the cities observed on the road network, which is also confirmed in the literature on the subject [45-48].

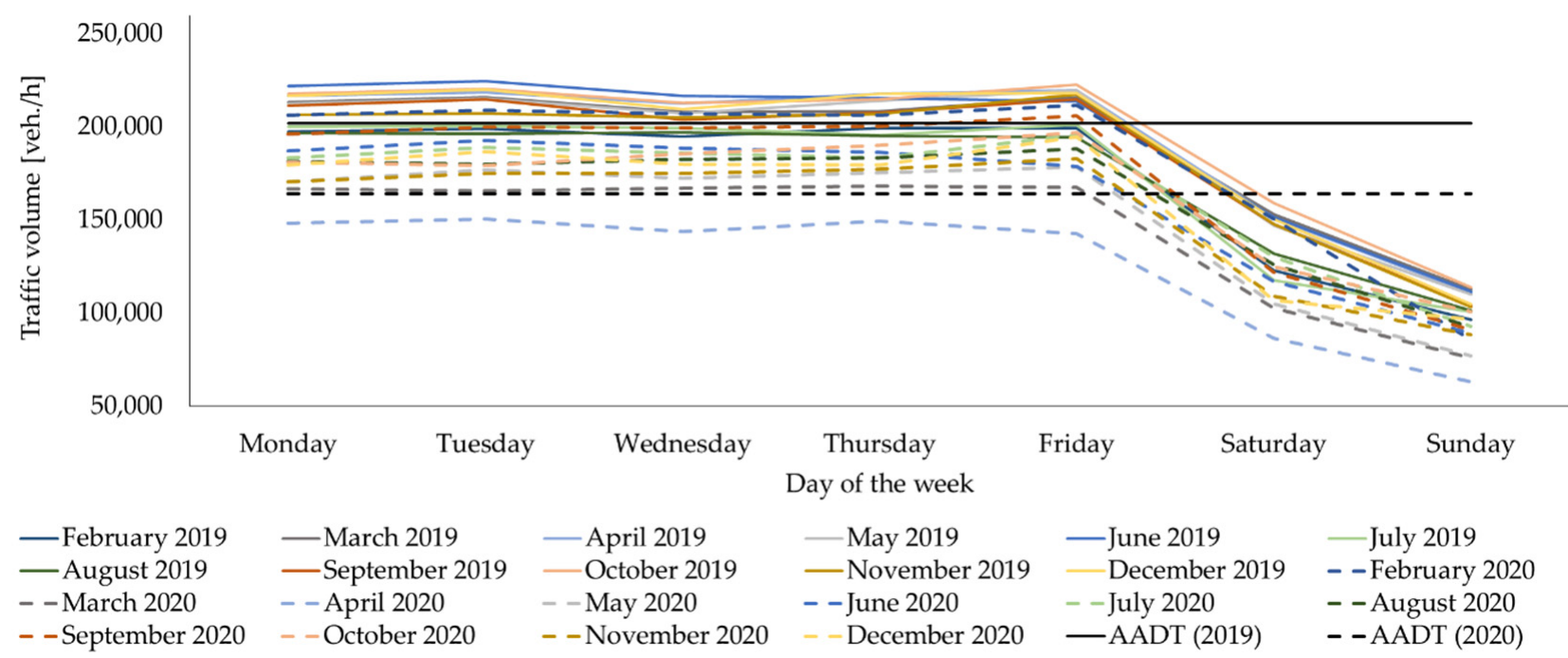

Figure 4. The total traffic volume at the analyzed intersections on particular days of the week in particular months in 2019 and 2020.

The total traffic volume on particular days of the week in particular months in 2020 was lower than in 2019 in all cases due to the covid-19 pandemic. AADT in 2020 was as much as $19 \%$ lower than AADT in 2019. In 2019, the values of traffic volume in February, July, and August were lower than the AADT value. This is due to the winter holidays (February) and summer holidays (July and August) in these months in Poland. In the case of 2020, the lowest values of traffic volume were recorded in March and April. The traffic volume is indeed a random variable, the value of which is influenced by many factors, but in the analyzed case the main determinant of low traffic volume in the above-mentioned months was the first wave of the covid-19 pandemic.

The traffic forecast for 2020 was determined for the analyzed intersections based on the data on traffic volume in 2019. The indicator annual percentage increase in road traffic volume $(W R)$ was used for this purpose [49]:

$$
W R=Q_{2019} \cdot\left(1+\frac{G D P \cdot W e}{100}\right)[\%]
$$

where:

WR-annual percentage increase in road traffic volume [\%],

$Q_{2019}$-traffic volume in 2019,

GDP_-gross domestic product (for Gliwice city for 2020 according to [49] GDP $=3.1 \%$ ),

We-flexibility factor; for passenger cars in 2016-2040. According to [49] We $=0.8$.

Figure 5 presents the distribution of total road traffic volume on working days in particular weeks in 2019 and 2020 and the forecast traffic volume for 2020 at all analyzed intersections. The highest values of traffic volume in 2019 occurred at intersections (3), (4), and (6). On the other hand, in 2020, the highest values of traffic volume occurred at intersections (3), (6), and (1). At intersections (2), and (5) were the lowest values of traffic volume, both in 2019 and in 2020. The forecasting traffic volume for 2020 is on average $1 \%$ higher than the traffic volume in 2019. Only in a few cases, the value of the forecast for 2020 is at a similar level as the actual values of traffic volume in 2020 . The accuracy of the forecast of traffic volume was confirmed for the following week numbers:

- $\quad$ intersection (1): 8, 35, 38,

- $\quad$ intersection (2): 8 , 
- $\quad$ intersection (3): 10, 27, 31, 36,

- intersection (4): 9,

- $\quad$ intersection (5): 8, 27, 29, 35, 36, 40,

- $\quad$ intersection (8): 8, 31 .

The forecast of traffic volume did not confirm in any week in the case of intersections (6) and (7). In 2020 the largest decrease in the value of traffic volume at all analyzed intersections occurred in the 12th -17th weeks compared to 2019.

At a later stage of the work, changes in the values of traffic volume in subsequent stages of the pandemic were analyzed (Figure 5). In Poland, the state of the epidemic was introduced on 20 March 2020, i.e., in the 12th week of the year. On 4 May 2020 (19th week), some retail and service outlets resumed their activities. A gradual increase in the value of traffic volume at all analyzed intersections occurred from the 19th week. From 1 September 2020, children returned to school for full-time education. From 1 October 2020, students began learning in a hybrid form, i.e., some classes were conducted in person, e.g., laboratories, projects, and exercises, and some in a remote form, e.g., lectures. During this period, there was also a noticeable further increase in traffic volume on the transport network (these are the 36th and 40th week of the year, respectively). From 23 October 2020 (43rd week), children and students resumed remote classes due to the constantly increasing number of new SARS-CoV-2 infections. The value of traffic volume on the transport network decreased from the 43rd week of 2020. The presented course of the restrictions introduced is reflected in changes in the value of traffic volume on the transport network. At all analyzed intersections (except intersections (6) and (7)), until the 8th week of the year, traffic volume in 2020 was higher than in 2019. Traffic volume decreased from the 9 th to the 14th week of 2020 (and in the case of intersection (2) in the 13th week). Then, at all analyzed intersections, except intersection (5), traffic volume increased and fluctuated in the 21st-34th weeks. The traffic volume increased from the 35 th week.

Then, depending on the intersection, traffic volume decreased again until the end of the year:

- $\quad$ intersection (1): 19 th week of 2020,

- intersection (2): 41st week of 2020,

- $\quad$ intersection (3): 43rd week of 2020,

- intersection (4): 42nd week of 2020,

- intersection (6): 44th week of 2020,

- intersection (7): 42nd week of 2020,

- $\quad$ intersection (8): 42nd week of 2020.

In the case of intersection (5), from the 14th to the 27th week of 2020, the value of traffic volume increased, and then, by the 40th week of 2020, the value of traffic volume was at a similar level as in 2019. From the 42nd week of 2020, traffic volume continued to decrease until the end of the year.

An important element of the analysis of the variability of traffic volume is the characteristic of their increase or decrease in the subsequent weeks of the year to AADT (Table 4). 


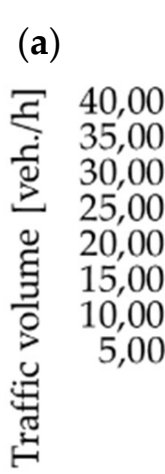

(b)

₹ 40,000

35,000

टं 30,000

$\pm 25,000$

20,000

르 10,000

> 5,000

进

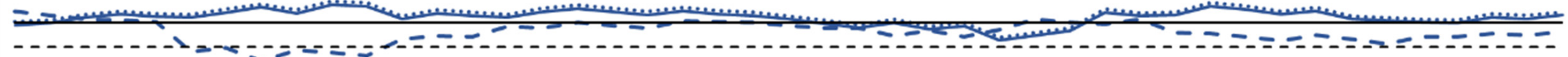

$7 \quad 8 \quad 9101112131415161718192021222324252627282930313233343536373839404142434445464748495051$ Week of the year

- $\mathrm{Q}(1)$ in $2019 \quad--\mathrm{Q}(1)$ in $2020 \quad \cdots \cdot \mathrm{Q}(1) \mathrm{F} \quad$-AADT (2019) - - AADT (2020)

-

$78 \quad 9101112131415161718192021222324252627282930313233343536373839404142434445464748495051$ Week of the year

Q $(2)$ in $2019--\mathrm{Q}(2)$ in $2020 \cdots . . . \mathrm{Q}(2) \mathrm{F}$ - AADT (2019) - - AADT (2020)

Figure 5. Cont. 
(c)

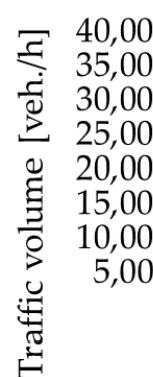

(d)

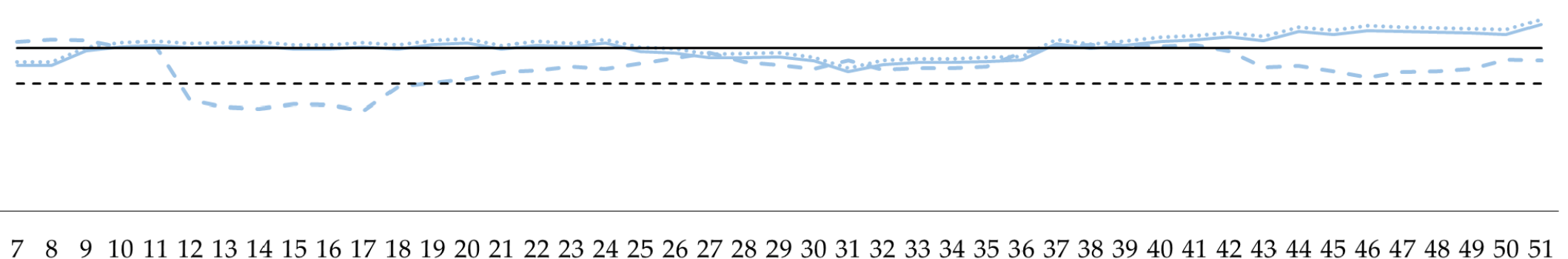
Week of teh year
Q(3) in 2019
- $\mathrm{Q}(3)$ in 2020
Q(3)F
— AADT (2019)
- - AADT (2020)

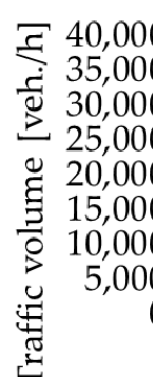

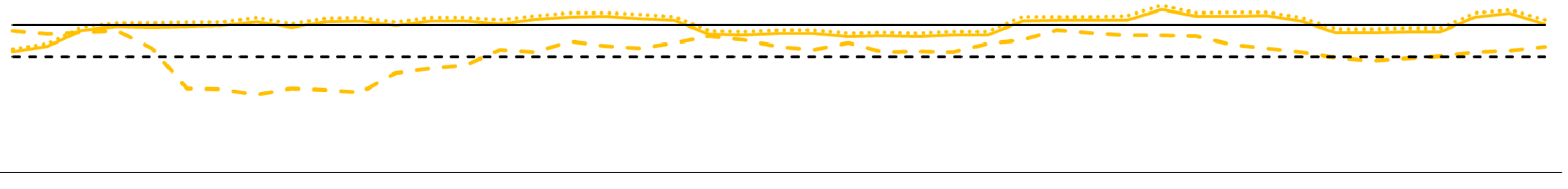

789101112131415161718192021222324252627282930313233343536373839404142434445464748495051 Week of the year

$-\mathrm{Q}(4)$ in $2019--\mathrm{Q}(4)$ in $2020 \cdots . . \mathrm{Q}(4) \mathrm{F}$-AADT (2019) - - AADT (2020)

Figure 5. Cont. 


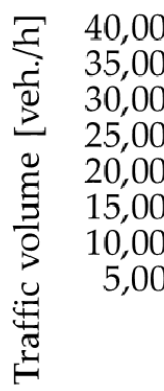

(2)

(f)

ב 40,000

ट̇ 35,000

30,000

$\geq 25,000$

20,000

g 15,000

등 10,000

5,000

胥

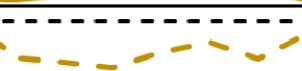

789101112131415161718192021222324252627282930313233343536373839404142434445464748495051 Week of the year
$-\mathrm{Q}(5)$ in 2019
$-Q(5)$ in 2020
$\cdots \mathrm{Q}(5) \mathrm{F}$
- AADT (2019)
- - AADT (2020)

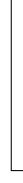

789101112131415161718192021222324252627282930313233343536373839404142434445464748495051 Week of the year

$\longrightarrow \mathrm{Q}(6)$ in $2019--\mathrm{Q}(6)$ in $2020 \cdots . . \mathrm{Q}(6) \mathrm{F}$-AADT (2019) - - AADT (2020)

Figure 5. Cont. 
(g)

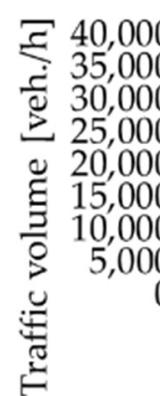

(h)

$$
\begin{aligned}
& \text { 다 40,000 } \\
& \text { ¿ } 35,000 \\
& \begin{array}{r}
30,000 \\
25,000
\end{array} \\
& \text { \& } 20,000 \\
& \text { छ } 15,000 \\
& 10,000 \\
& \begin{array}{rr}
5,000 \\
0
\end{array} \\
& \text { 莺 }
\end{aligned}
$$

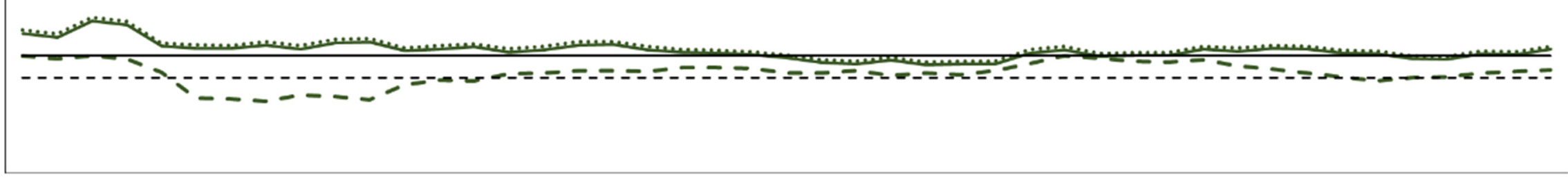

789101112131415161718192021222324252627282930313233343536373839404142434445464748495051 Week of the year

$$
\text { —Q(7) in } 2019--Q(7) \text { in } 2020 \cdots \cdots \mathrm{Q}(7) \mathrm{F} \text { - AADT (2019) - - - AADT (2020) }
$$

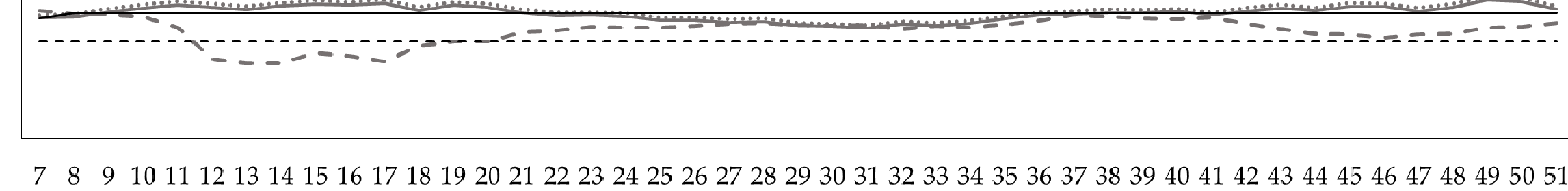$$
-
$$

7899101112131415161718192021222324252627282930313233343536373839404142434445464748495051

Week of the year

$$
-\mathrm{Q}(8) \text { in } 2019 \quad-\quad \mathrm{Q}(8) \text { in } 2020 \quad \cdots . . \mathrm{Q}(8) \mathrm{F} \quad \text { - AADT (2019) - - AADT (2020) }
$$

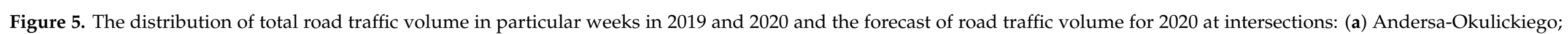

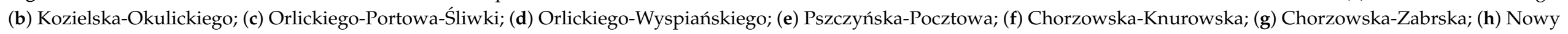

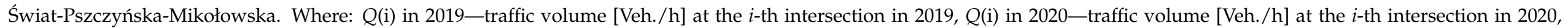
Q(i)F-traffic volume forecast in 2020, AADT (2019)—the annual average daily traffic volume in 2019, AADT (2020)—the annual average daily traffic volume in 2020. 
Table 4. Road traffic variability factors in the following weeks of the year.

\begin{tabular}{|c|c|c|c|c|c|c|c|c|c|c|c|c|c|c|c|c|c|}
\hline \multirow{2}{*}{$\begin{array}{c}\text { Week } \\
\text { of the } \\
\text { Year }\end{array}$} & \multicolumn{8}{|c|}{$\begin{array}{c}\text { The Road Traffic Variability Factors } \\
{[\%]}\end{array}$} & \multirow{2}{*}{$\begin{array}{c}\text { Week } \\
\text { of the } \\
\text { Year }\end{array}$} & \multicolumn{8}{|c|}{$\begin{array}{c}\text { The Road Traffic Variability Factors } \\
{[\%]}\end{array}$} \\
\hline & (1) & (2) & (3) & (4) & (5) & (6) & (7) & (8) & & (1) & (2) & (3) & (4) & (5) & (6) & (7) & (8) \\
\hline 7 & 8.83 & -4.02 & 3.93 & -3.37 & -0.01 & -10.30 & -0.48 & 5.96 & 30 & -4.20 & -4.57 & -12.85 & -16.82 & -0.50 & -18.33 & -14.64 & -6.78 \\
\hline 8 & 5.76 & -3.99 & 5.38 & -5.44 & 0.51 & -5.90 & -2.67 & 3.66 & 31 & -4.58 & -2.74 & -7.42 & -11.80 & 2.87 & -17.91 & -12.71 & -5.64 \\
\hline 9 & 2.47 & -4.87 & 4.76 & -4.37 & -3.82 & -4.86 & -0.35 & 3.17 & 32 & -10.67 & -9.53 & -13.36 & -18.22 & -2.91 & -19.66 & -16.95 & -9.08 \\
\hline 10 & 2.28 & -1.71 & 0.36 & -3.62 & 2.13 & -7.99 & -3.00 & 1.28 & 33 & -5.99 & -4.11 & -12.40 & -17.61 & -3.13 & -20.68 & -15.05 & -6.65 \\
\hline 11 & 0.54 & -12.28 & 1.18 & -15.60 & -3.87 & -3.93 & -14.29 & -7.70 & 34 & -10.92 & -8.52 & -12.57 & -18.10 & -3.02 & -20.00 & -16.49 & -8.15 \\
\hline 12 & -23.05 & -31.54 & -31.93 & -42.86 & -31.94 & -25.27 & -36.19 & -34.00 & 35 & -5.65 & -4.01 & -11.27 & -12.51 & 3.41 & -17.90 & -12.82 & -5.12 \\
\hline 13 & -20.01 & -35.23 & -35.91 & -43.42 & -34.93 & -17.69 & -36.96 & -37.07 & 36 & 2.78 & 1.58 & -3.09 & -9.58 & 0.76 & -12.41 & -7.09 & -1.91 \\
\hline 14 & -30.71 & -28.99 & -37.16 & -46.88 & -37.90 & -29.49 & -39.11 & -36.75 & 37 & 0.14 & 0.97 & 1.29 & -2.97 & 2.20 & -8.44 & -0.16 & 2.83 \\
\hline 15 & -22.12 & -26.69 & -34.36 & -42.68 & -28.49 & -20.86 & -33.52 & -28.92 & 38 & -1.43 & 2.07 & 1.79 & -4.78 & 1.20 & -7.19 & -2.54 & 1.18 \\
\hline 16 & -23.63 & -30.54 & -34.67 & -44.06 & -22.79 & -29.54 & -35.13 & -31.33 & 39 & 2.59 & -3.79 & 1.69 & -6.76 & -0.23 & -8.77 & -4.67 & -0.20 \\
\hline 17 & -26.24 & -32.82 & -38.67 & -45.70 & -32.87 & -28.68 & -37.74 & -35.99 & 40 & -7.81 & -4.42 & 1.15 & -6.74 & -0.21 & -9.98 & -5.69 & -0.86 \\
\hline 18 & -13.37 & -15.78 & -23.71 & -32.38 & -16.83 & -22.74 & -24.66 & -23.07 & 41 & -8.57 & 0.33 & 1.84 & -7.37 & 1.59 & -6.75 & -3.66 & 0.61 \\
\hline 19 & -10.27 & -13.21 & -21.17 & -29.46 & -8.33 & -21.36 & -20.96 & -19.17 & 42 & -11.24 & -12.08 & -1.84 & -13.06 & 1.57 & -10.72 & -9.15 & -4.78 \\
\hline 20 & -11.19 & -13.80 & -18.89 & -27.03 & -7.21 & -23.41 & -21.56 & -19.39 & 43 & -14.38 & -12.06 & -11.94 & -15.81 & -5.85 & -11.58 & -11.47 & -9.34 \\
\hline 21 & -3.21 & -6.70 & -14.81 & -16.41 & -3.15 & -14.71 & -15.54 & -11.72 & 44 & -9.90 & -13.75 & -11.17 & -18.36 & -6.26 & -10.88 & -14.57 & -12.60 \\
\hline 22 & -4.53 & -5.90 & -13.71 & -18.22 & 0.85 & -17.22 & -14.85 & -10.21 & 45 & -12.82 & -14.41 & -14.22 & -22.00 & -8.56 & -14.99 & -18.35 & -13.31 \\
\hline 24 & -2.42 & -2.87 & -12.66 & -13.86 & -0.31 & -23.94 & -12.74 & -7.67 & 47 & -11.26 & -15.50 & -14.54 & -22.39 & -3.20 & -9.61 & -19.07 & -13.33 \\
\hline 25 & -4.57 & -5.27 & -9.73 & -15.47 & -1.86 & -18.15 & -13.64 & -8.11 & 48 & -11.51 & -15.08 & -14.26 & -20.79 & -5.92 & -14.29 & -17.98 & -13.18 \\
\hline 26 & 1.20 & -0.67 & -6.26 & -11.67 & 3.25 & -15.18 & -10.37 & -6.66 & 49 & -8.73 & -10.57 & -12.66 & -18.18 & -6.34 & -10.77 & -15.16 & -8.10 \\
\hline 27 & 0.99 & -3.48 & -2.84 & -7.37 & 10.26 & -16.54 & -10.40 & -4.84 & 50 & -9.98 & -12.67 & -7.34 & -17.40 & -9.03 & -9.78 & -13.77 & -7.25 \\
\hline 28 & -0.04 & -1.78 & -8.57 & -9.70 & 12.57 & -13.59 & -10.74 & -4.10 & 51 & -7.39 & -6.65 & -7.41 & -14.55 & -7.46 & -9.96 & -12.07 & -4.02 \\
\hline 29 & -2.17 & -3.17 & -10.58 & -14.31 & 1.93 & -15.60 & -14.75 & -5.93 & & & & & & & & & \\
\hline
\end{tabular}


The AADT value was adopted as the reference level from 2019 due to the specificity of 2020. Hence, the variability of the value of traffic volume in the subsequent weeks of 2020 to the AADT from 2019 was determined using the formula:

$$
V I_{i}=\left(\frac{Q_{i-2020}-A A D T_{2019}}{A A D T_{2019}}\right) \cdot 100[\%]
$$

where:

$V I_{i}$-road traffic variability factor in the i-th week of the year [\%],

$Q_{i-2020}$-road traffic volume in the i-th week of 2020 [Veh./h],

$A A D T_{2019}$ - the annual average daily traffic volume in 2019 [Veh./h].

The largest differences between the values of traffic volume and the AADT for 2019 occured in the weeks of partial and full lockdown based on the value of the road traffic variability factor in the following weeks of the year. In the remaining cases, these differences take small values.

For all analyzed intersections, the AADT variability factor for 2019-2020 was determined in the same way:

$$
V I_{A A D T}=\left(\frac{A A D T_{2020}-A A D T_{2019}}{A A D T_{2019}}\right) \cdot 100[\%]
$$

where:

$V I$-road traffic variability factor for AADT [\%],

$A A D T_{2020}$ - the annual average daily traffic volume in 2020 [Veh./h],

$A A D T_{2019}$ - annual average daily traffic in 2019 [Veh./h].

Table 5 shows that, in all cases, a significant decrease in traffic volume is visible, ranging from $-9.68 \%$ to $-23.05 \%$ depending on the intersection.

Table 5. Road traffic variability factor for AADT in 2019 and 2020.

\begin{tabular}{ccccccccc}
\hline Intersection & $\mathbf{( 1 )}$ & $\mathbf{( 2 )}$ & $\mathbf{( 3 )}$ & $\mathbf{( 4 )}$ & $\mathbf{( 5 )}$ & $\mathbf{( 6 )}$ & $\mathbf{( 7 )}$ & $\mathbf{( 8 )}$ \\
\hline$V I_{A A D T}[\%]$ & -19.63 & -23.05 & -21.86 & -21.59 & -9.68 & -15.48 & -18.68 & -19.35 \\
\hline
\end{tabular}

\section{Characteristics of the Daily Variability of Traffic Volume in 2019 and 2020}

The daily road traffic volume distribution in particular weeks in 2019 and 2020 were examined (Figure 6) in the next step of the analysis. The road traffic volume distribution in particular hours on working days usually shows certain patterns on specific types of roads. Knowledge of the values of traffic volume during the day and their variability allows for the determination of several measures and parameters assessing traffic conditions prevailing on the elements of transport networks. Knowledge and understanding of changes in the distribution of traffic volume during a day are crucial for many aspects of transport engineering, such as road traffic control, road safety, and forecasting traffic volume. The distribution of traffic volume in particular hours of the day is characterized by a smaller spread of particular profiles per day in 2019, at all intersections, than in 2020. Moreover, in 2020, the morning and afternoon rush hours show a greater flattening than in 2019. In 2019, the morning rush hours at intersections (1), (2), (4), (6) occurred from 06:00-07:00, while at intersections (3), (5), (7), (8) from 06:00 to 08:00. In turn, the afternoon rush hours at all analyzed intersections occurred between 14:00-17:00. 
(a)

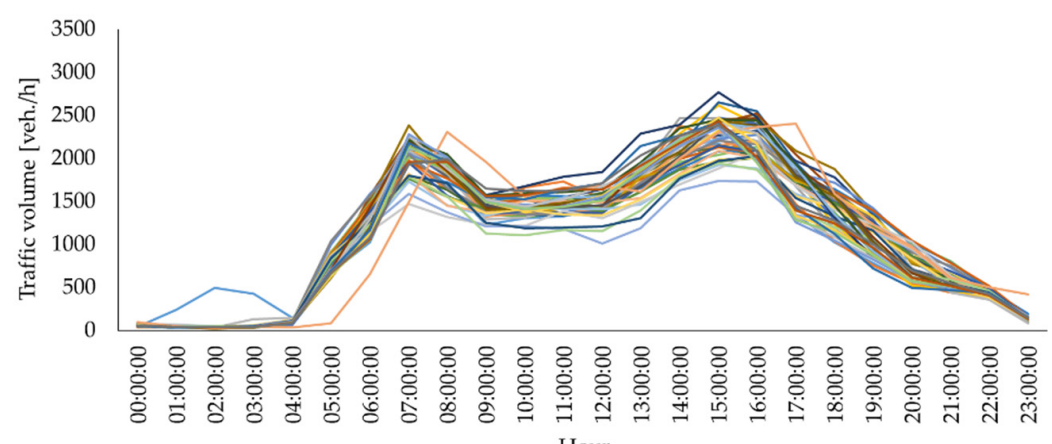
Hour

-7 week -8 week -9 week -10 week -11 week -12 week -13 week -14 week -15 week -16 week -17 week -18 week -19 week -20 week -21 week -22 week -23 week -24 week -25 week -26 week -27 week -28 week -29 week -30 week -31 week -32 week - 33 week -34 week -35 week -36 week -37 week -38 week -39 week -40 week -41 week -42 week

$$
3500
$$

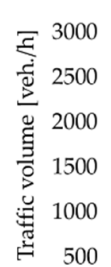

丞 500

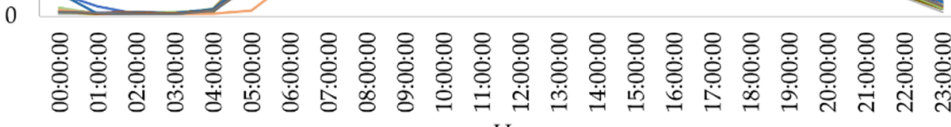
Hour

-7 week -8 week -9 week -10 week -11 week -12 week -13 week -14 week -15 week -16 week -17 week -18 week -19 week -20 week -21 week -22 week -23 week -24 week -25 week -26 week -27 week -28 week -29 week -30 week -31 week -32 week -33 week -34 week -35 week -36 week -37 week -38 week -39 week -40 week -41 week -42 week -43 week -44 week -45 week -46 week -47 week -48 week -49 week -50 week -51 week

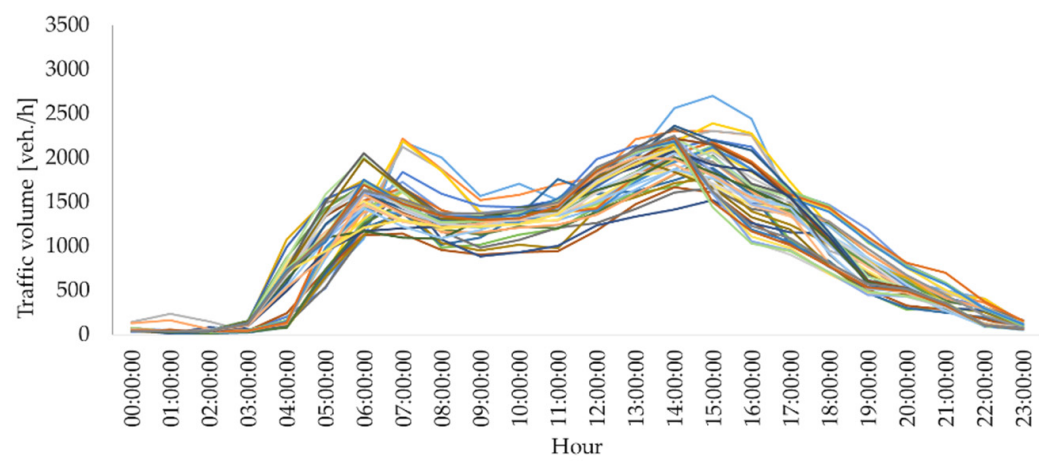

-7 week -8 week -9 week -10 week -11 week -12 week -13 week -14 week -15 week -16 week - 17 week 18 week -19week 20 week 21 week 22 week -23 week 24 week - 25week - 26 wek -27 week -28 weck-29week 30 week 31 week 32 week 33 week -43 week 44 week 45 week 46 week -47 week -48 week -49 week - 50 week -51 week

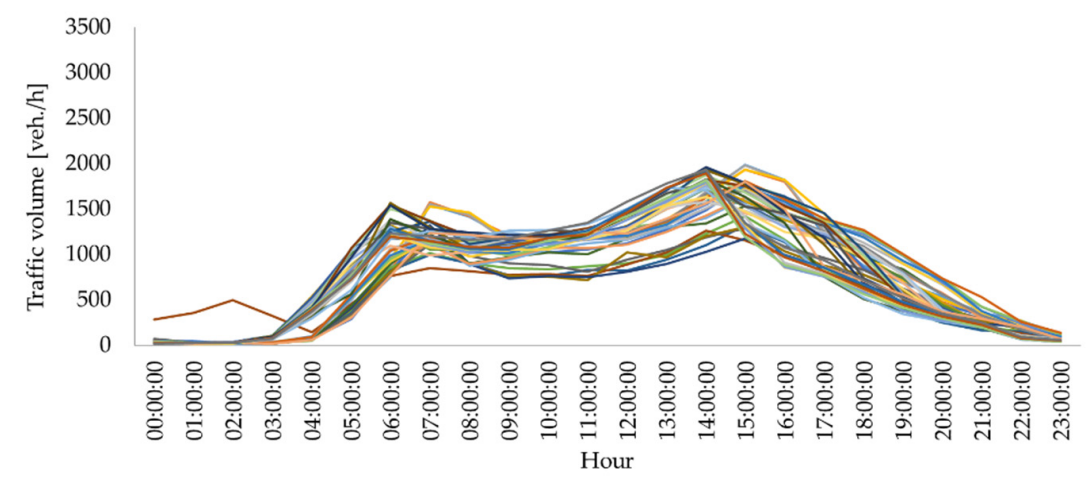

-7 week -8 week -9 week -10 week -11 week -12 week -13 week -14 week -15 week -16 week -17 week -18 week -19 week -20 week -21 week -22 week -23 week -24 week -25 week -26 week -27 week -28 week -29 week -30 week -31 week -32 week -33 week -43 week -44 week -45 week -46 week -47 week -48 week -49 week -50 week -51 week

Figure 6. Cont. 
(e)

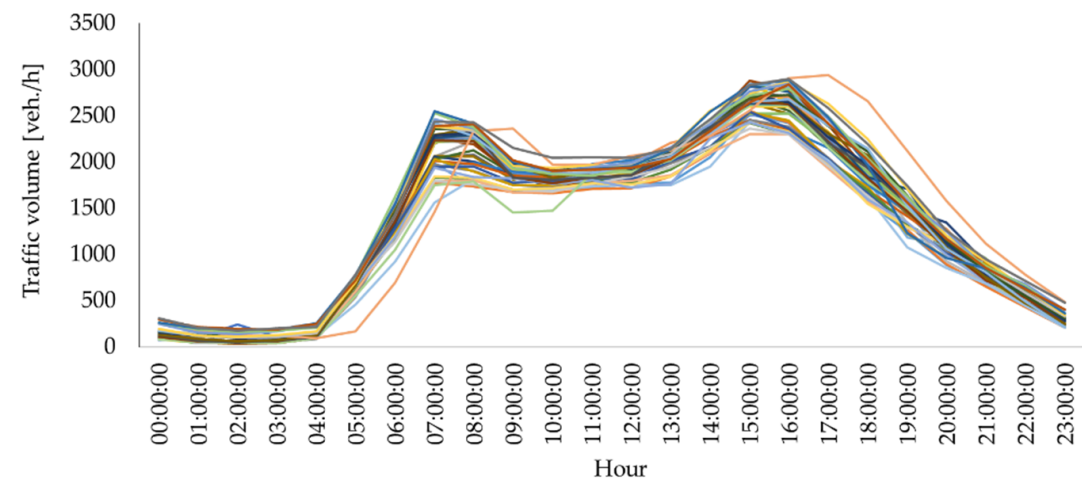

-7 week -8 week -9 week -10 week -11 week -12 week -13 week -14 week -15 week -16 week -17 week -18 week -19 week -20 week -21 week -22 week -23 week -24 week -25 week -26 week -27 week -28 week -29 week -30 week -31 week -32 week -33 week 34 week -35 week -36 week -37 week -38 week -39 week -40 week -41 week -42 week
-43 week -44 week -45 week -46 week -47 week -48 week -49 week -50 week -51 week

$(\mathrm{g})$

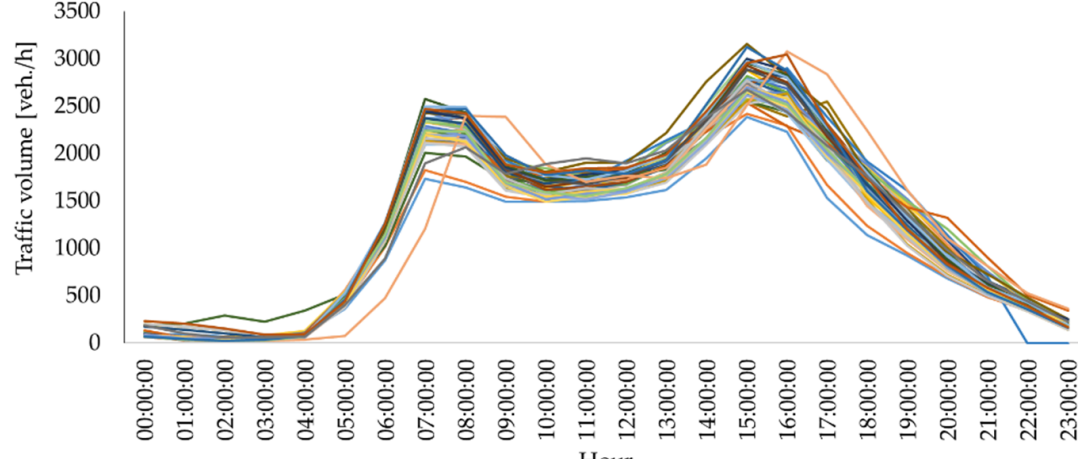

-7 week -8 week -9 week -10 week -11 week -12 week -13 week -14 week -15 week -16 week -17 week -18 week -19 week -20 week -21 week -22 week -23 week -24 week -25 week -26 week -27 week -28 week -29 week -30 week -31 week -32 week -33 week -34 week -35 week -36 week -37 week -38 week -39 week -40 week -41 week -42 week
-43 week -44 week -45 week -46 week -47 week -48 week -49 week -50 week -51 week (f)

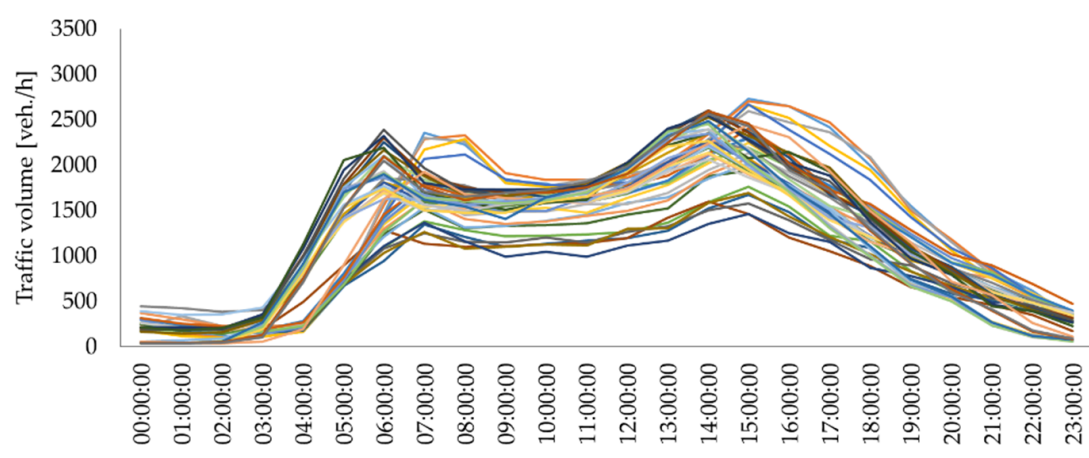
Hour

-7 week -8 week -9 week -10 week -11 week -12 week -13 week -14 week -15 week -16 week -17 week -18 week -19 week -20 week -21 week -22 week -23 week -24 week -25 week - 26week - 27week - 28week-29week - 30 week - 31 week - 32 week - 33 week -34 week -35 week -36 week -37 week -38 week -39 week - 40 week - 41 week - 42 week

(h)

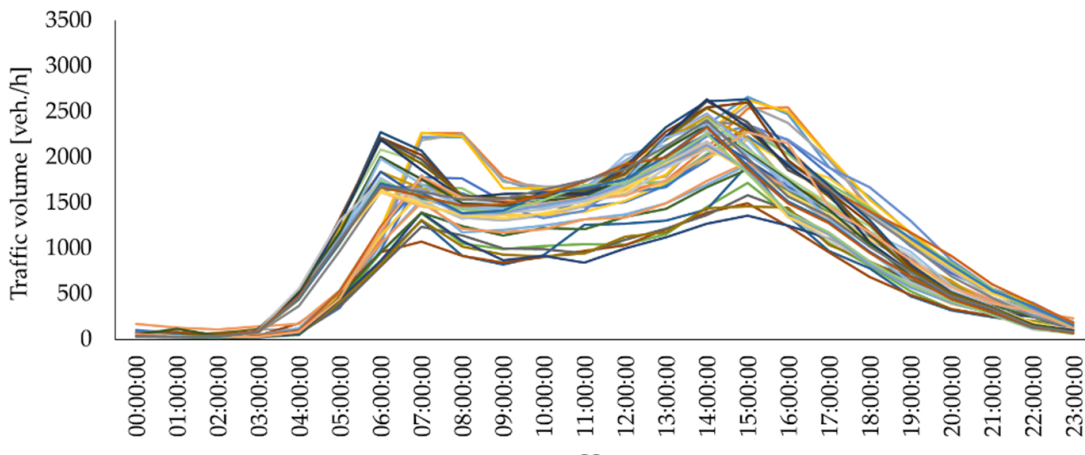
Hour

-7 week -8 week -9 week -10 week -11 week -12 week -13 week -14 week -15 week -16 week -17 week -18 week -19 week -20 week -21 week -22 week -23 week -24 week -25 week -26 week -27 week -28 week -29 week -30 week -31 week -32 week -33 week -43 week -44 week -45 week -46 week -47 week -48 week -49 week -50 week -51 week
-45

Figure 6. Cont. 
(i)

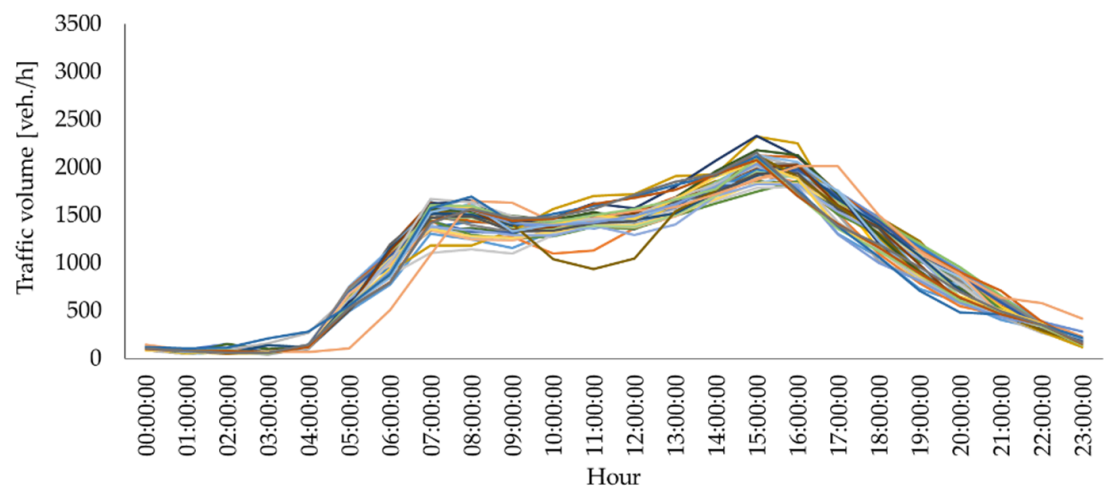

-7 week -8 week -9 week -10 week -11 week -12 week -13 week -14 week -15 week -16 week -17 week -18 week -19 week -20 week -21 week -22 week -23 week -24 week -25 week -26 week -27 week -28 week -29 week -30 week -31 week -32 week -33 week -34 week -35 week -36 week -37 week -38 week -39 week -40 week -41 week -42 week
-43 week -44 week -45 week -46 week -47 week -48 week -49 week -50 week -51 week

$(\mathbf{k})$

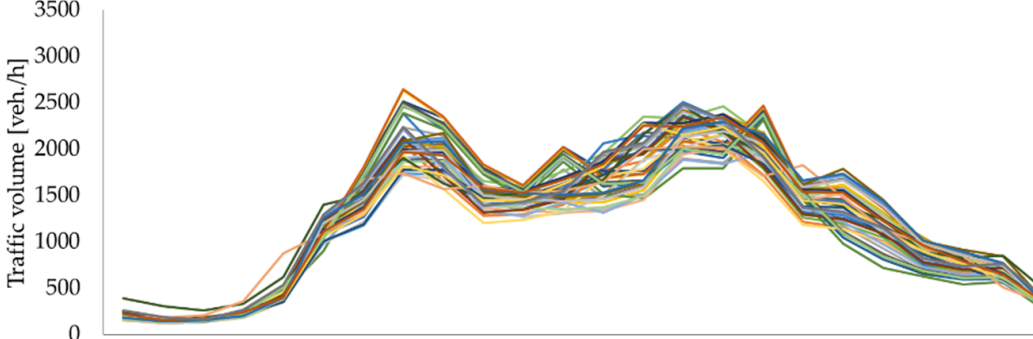

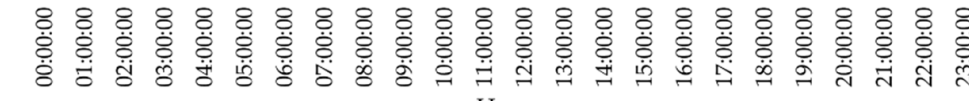
Hour

-7 week -8 week -9 week -10 week - 11 week -12 week - 13 week - 14 week -15 weck -16 week -17 weck-18wek - 19 weck - 20 week - 21 wek - 22 week -23 weck - 24 weck -16 week -17 week -18 week -19 week -20 week -21 week -22 week -23 week -24 week 34 week -35 week -36 week -37 week -38 week -39 week -40 week -41 week -42 week -43 week -44 week -45 week -46 week -47 week -48 week -49 week -50 week -51 week (j)

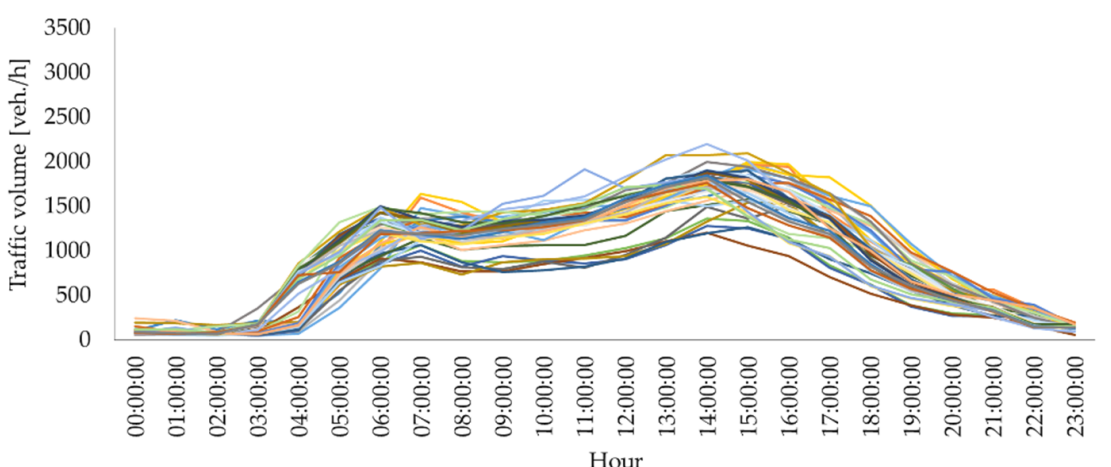

-7 week -8 week -9 week -10 week -11 week -12 week -13 week -14 week -15 week -16 week -17 week -18 week -19 week -20 week -21 week -22 week -23 week -24 week -25 week -26 week -27 week -28 week -29 week -30 week -31 week -32 week -33 week 34 week -35 week -36 week -37 week -38 week -39 week -40 week -41 week -42 week (1)

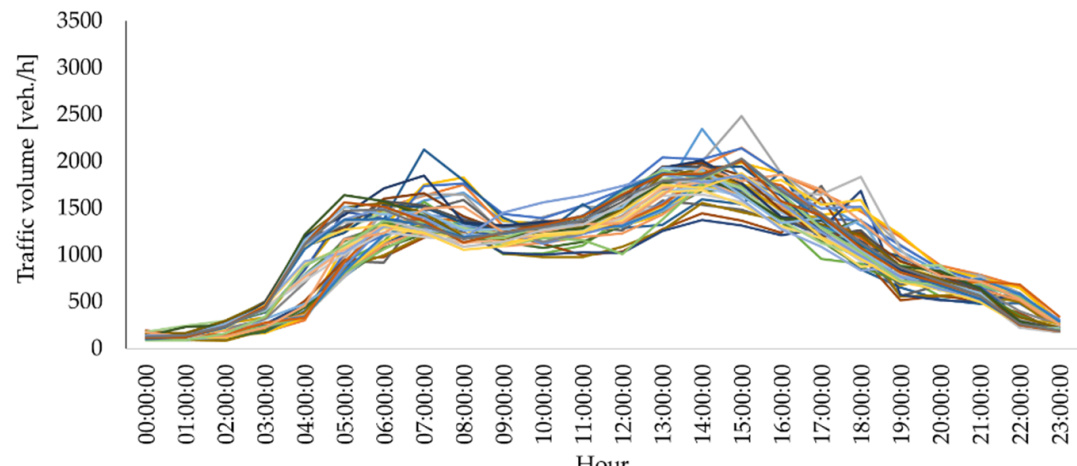
Hour

-7 week -8 week -9 week -10 week -11 week -12 week -13 week -14 week -15 week -16 week -17 week -18 week -19 week -20 week -21 week -22 week -23 week -24 week -25 week -26 week -27 week -28 week -29 week -30 week -31 week -32 week -33 week -43 week -44 week -45 week -46 week -47 week -48 week -49 week -50 week -51 week

Figure 6. Cont. 
(m)

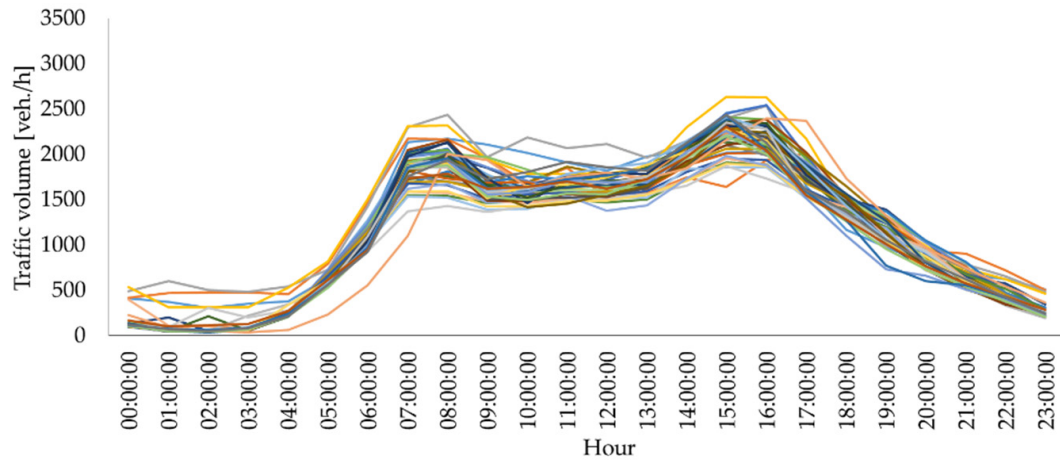

-7 week -8 week -9 week -10 week -11 week -12 week -13 week -14 week -15 week

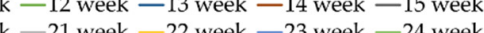
-25 week -26 week -27 week -28 week -29 week -30 week -31 week -32 week -33 week 34 week -35 week -36 week -37 week -38 week -39 week -40 week -41 week -42 week -43 week -44 week -45 week -46 week -47 week -48 week -49 week -50 week -51 week

(o)

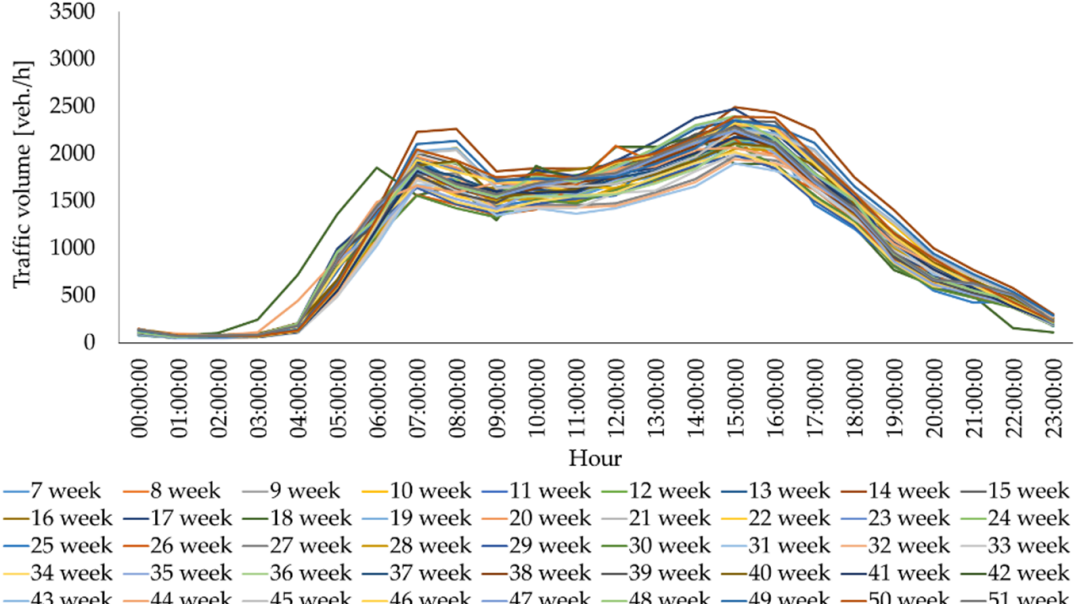

(n)

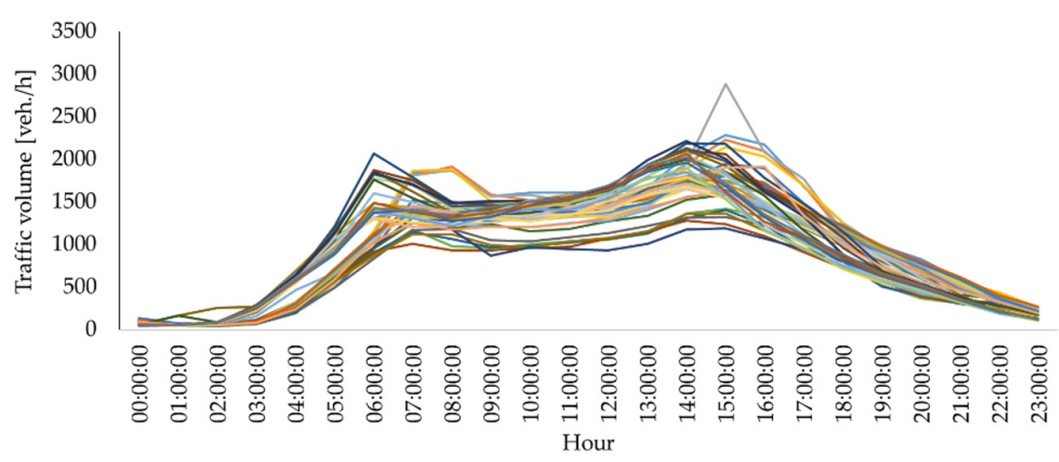

-7 week -8 week -9 week -10 week -11 week -12 week -13 week -14 week -15 week -16 week -17 week -18 week -19 week -20 week -21 week -22 week -23 week -24 week -25 week -26 week -27 week -28 week -29 week -30 week -31 week -32 week -33 week
-34 week -35 week -36 week -37 week -38 week -39 week -40 week -41 week -42 week 34 week -35 week -36 week -37 week -38 week -39 week -40 week -41 week -42 week
-43 week -44 week -45 week -46 week -47 week -48 week -49 week -50 week -51 week

$(\mathbf{p})$

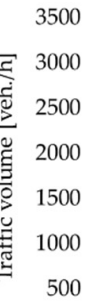

0
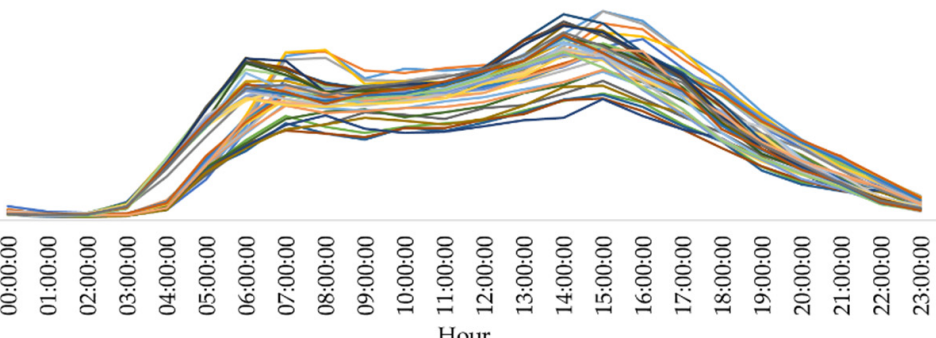

Ho

-7 week -8 week -9 week -10 week -11 week -12 week -13 week -14 week -15 week -16 week -17 week -18 week -19 week -20 week -21 week -22 week -23 week -24 week 34 week - 35 week -36 week - 37 week -38 week -39 week -40 week -41 week -43 week - 43 week - 44 week -45 week -46 week -47 week - 48 week -49 week -50 week - 51 week

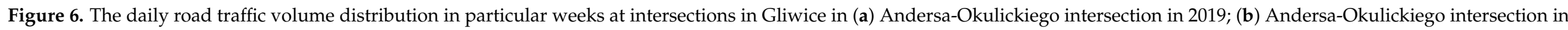

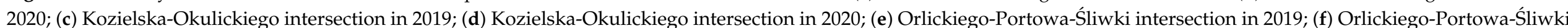

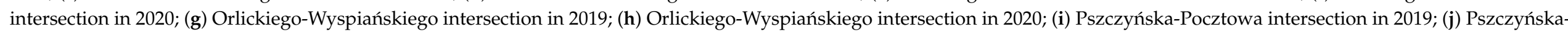

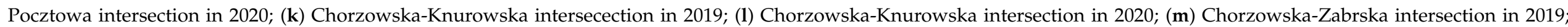
(n) Chorzowska-Zabrska intersection in 2020; (o) Nowy Świat-Pszczyńska-Mikołowska intersection in 2019; (p) Nowy Świat-Pszczyńska-Mikołowska intersection in 2020. 
In 2020, until the 12th week, the morning and afternoon rush hours at the analyzed intersections occurred at the same hours as in 2019. On the other hand, from the 12th week of 2020, the morning rush hours at intersections (1), (2), (3), (4), (7), (8) took place between 05:00-06:00, while at intersections (5), (6) between 04:00 and 06:00. The afternoon rush hours at all analyzed intersections after the 12th week of 2020 took place between 13:00-16:00.

In the next stage of work, the analysis covered the average values of traffic volume for each hour during the day in particular months of the year (Figure 7). These analyses were carried out for both 2019 and 2020. Both daily and monthly variability is visible for each intersection, with a clear increase in the value of traffic volume during the morning and afternoon rush hours. The distribution of traffic volume in 2020 is characterized by lower daily variability than in 2019 in each month of the year (except February) for each intersection. In addition, there is a different distribution of traffic volume in April 2020, characterized by much lower hourly traffic volume than in April 2019 or in other months of the year. In particular months of 2019, the morning and afternoon rush hours at each of the analyzed intersections occur at similar hours of the day. This regularity is no longer observed in 2020. Figure 7 shows a significant daily blurring of traffic volume distributions in particular months of 2020, which is probably largely related to the covid-19 pandemic. 

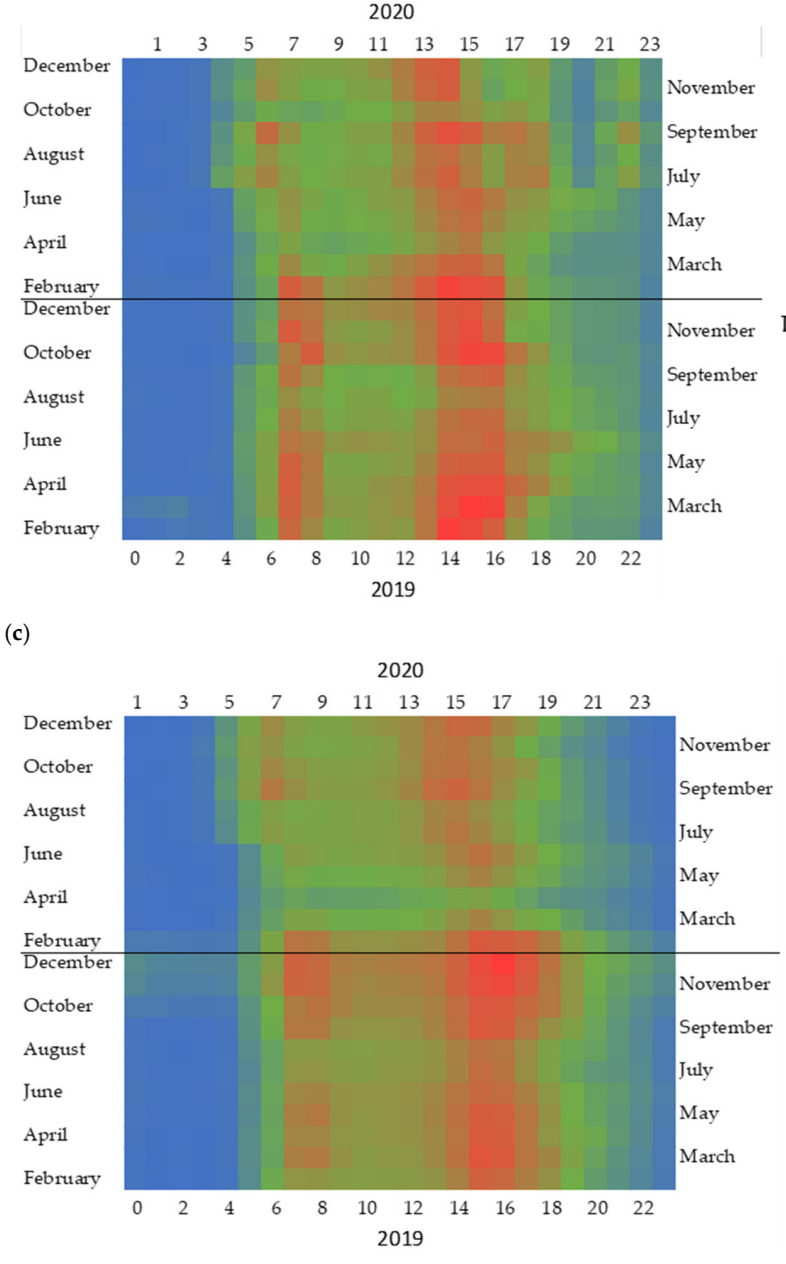

(b)
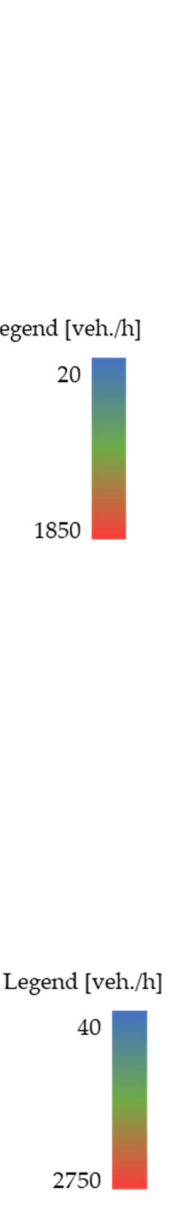

(d)
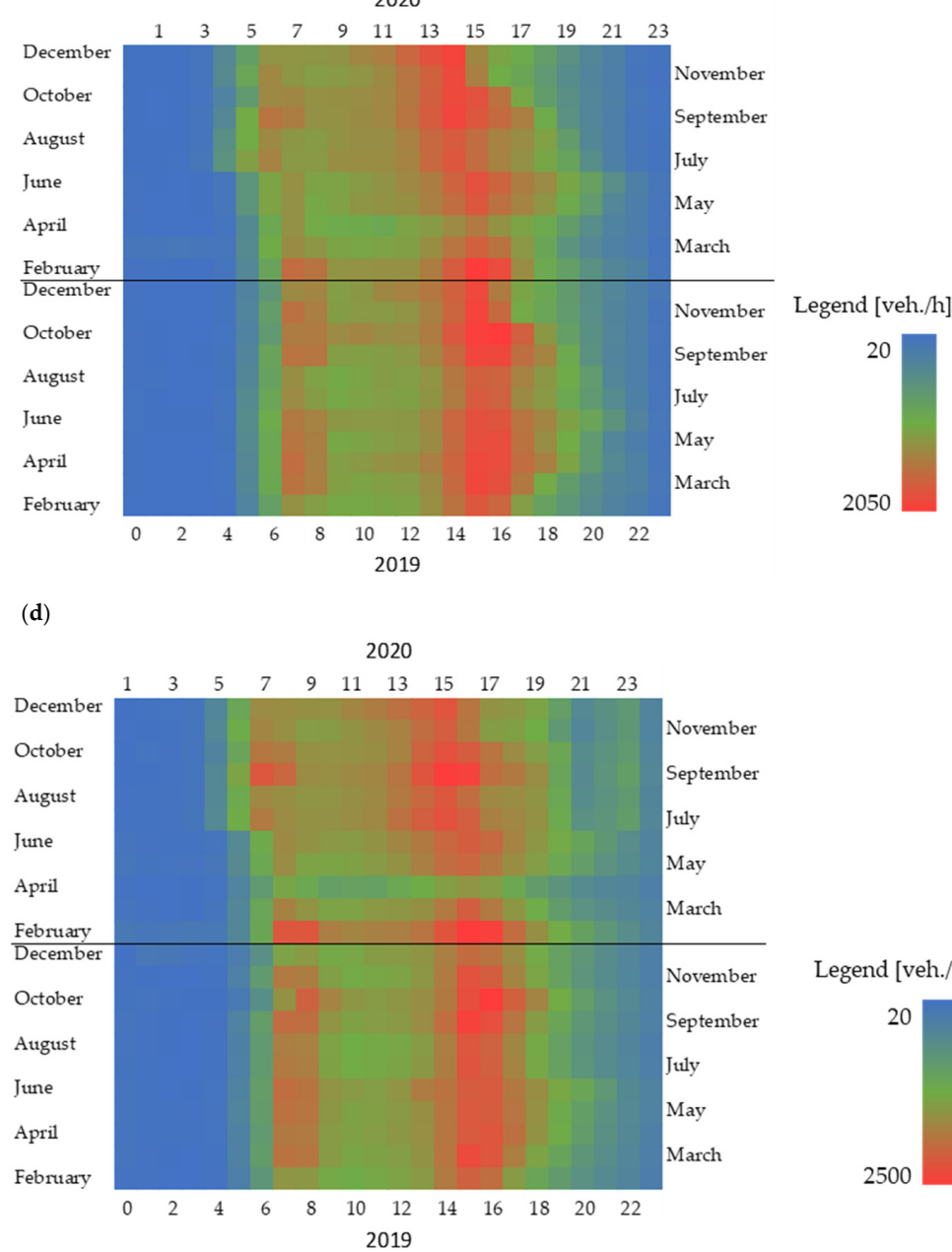

Legend [veh./h]

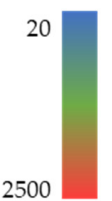

Figure 7. Cont. 
(e)
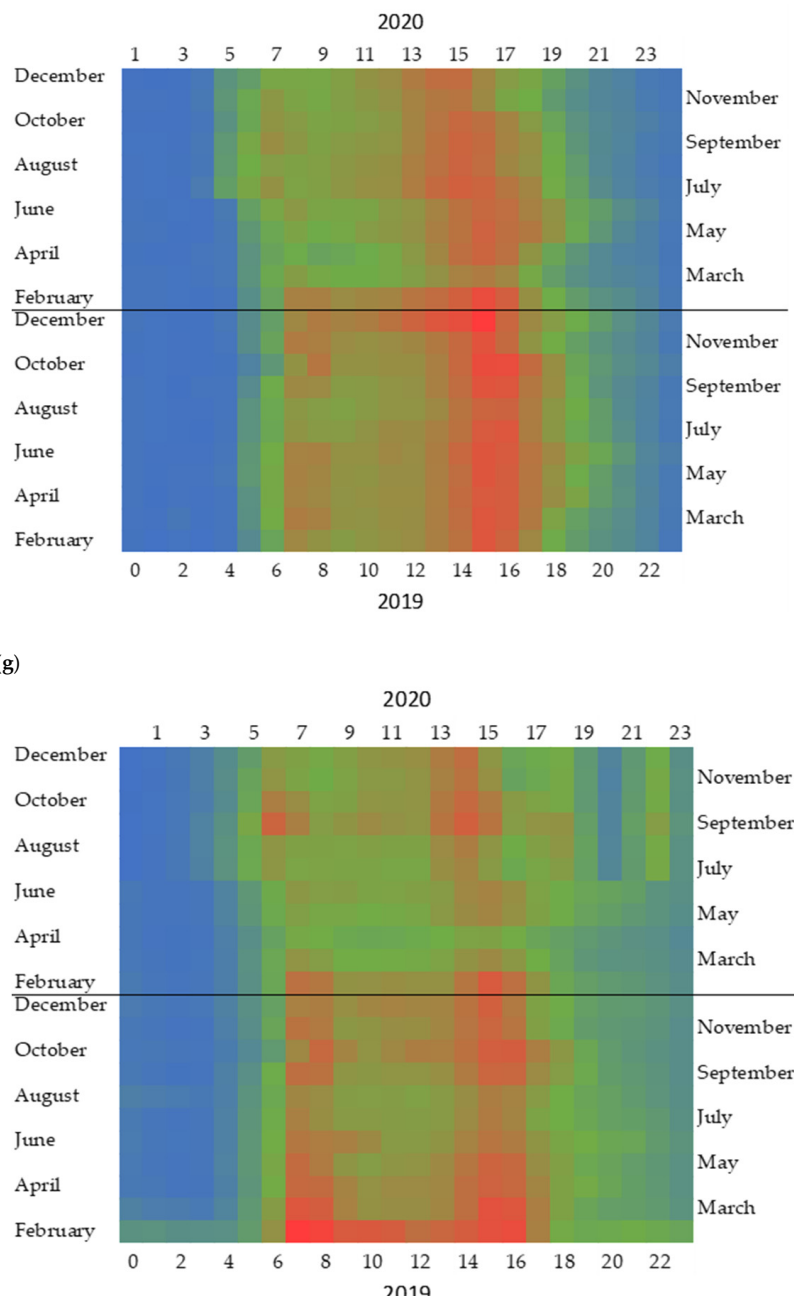

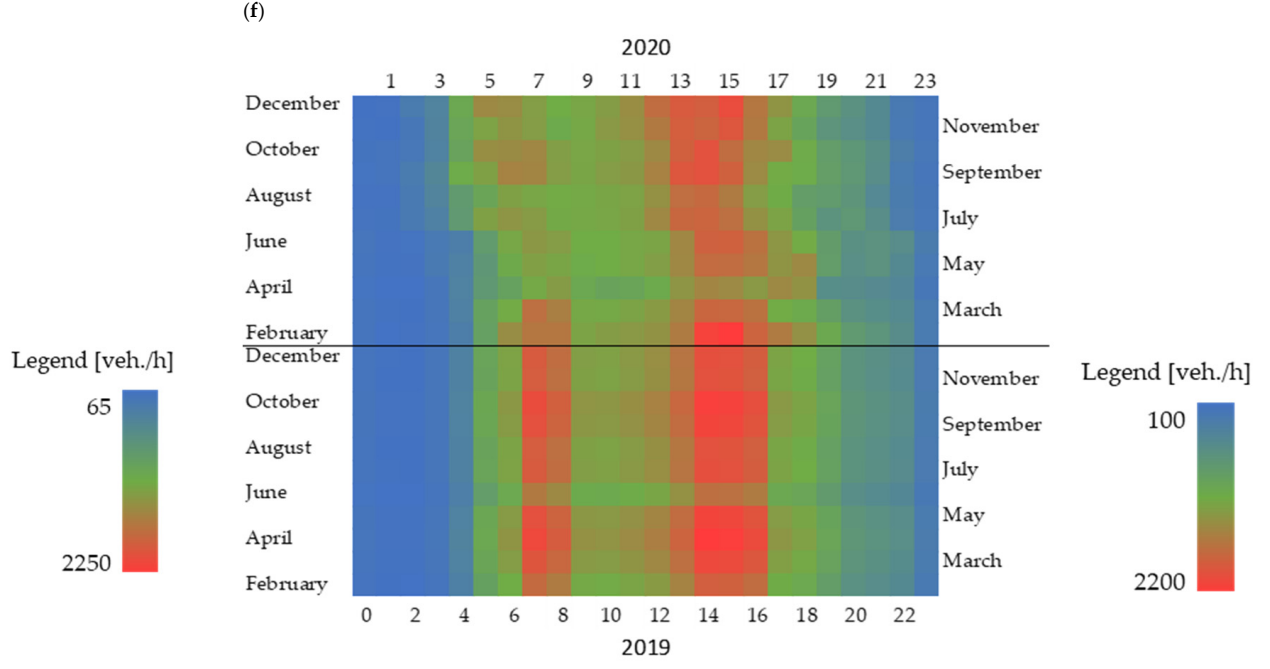

(h)

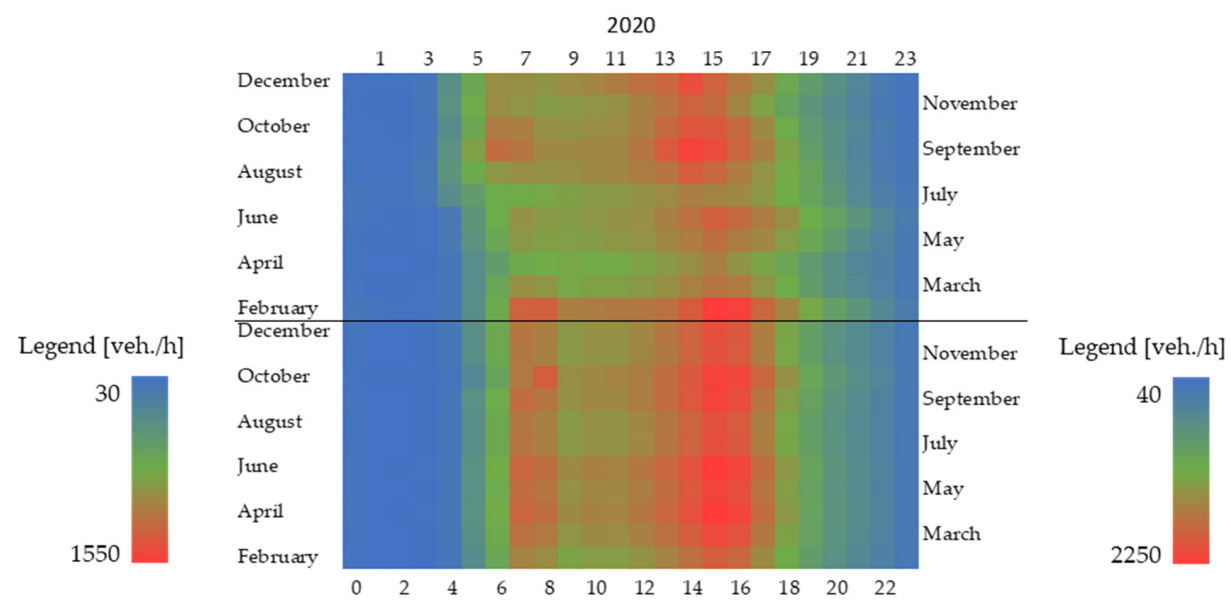

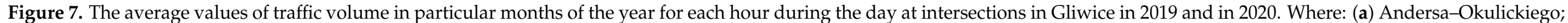

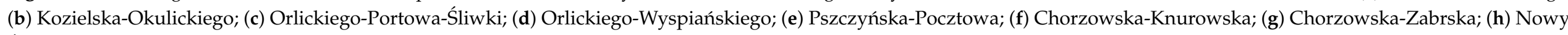
Świat-Pszczyńska-Mikołowska. 


\section{Daily Traffic Patterns at Particular Stages of a Pandemic}

Earlier analyses showed a different character of daily traffic volume distribution in particular stages of the covid-19 pandemic from the daily traffic distribution in the corresponding weeks of 2019. Hence, an attempt was made to estimate daily traffic patterns at particular stages of the covid-19 pandemic. The daily traffic patterns of this type were also constructed for the corresponding weeks in 2019. The comparison of these types of daily traffic patterns will enable the identification of general differences in the daily traffic patterns in 2019 and 2020. Estimated daily traffic patterns can be a source of information in traffic management in subsequent waves of the pandemic and other crises, reflected in a significant reduction in mobility and decrease in the value of traffic volume. Therefore, the following weeks of 2020, representing different stages of the pandemic, were selected for further detailed analysis:

- 17-23 February 2020: 8th week of the year (the average week before the pandemic period),

- 16-22 March 2020: 12th week of the year (which was also the first full week of lockdown in Poland),

- 20-26 April 2020: 17th week of the year (a week at lockdown),

- 18-24 May 2020: 21st week of the year (in the stage of partial opening of the country's economy),

- 22-28 June 2020: 26th week of the year (after the reopening of most services while maintaining the required sanitary regime, after the end of the school and academic year).

In the first stage of the work, the analysis covered changes in the value of traffic volume during the day for the original 15-min measurement data and aggregated it to hourly data (Figure 8).

In the case of data with a 15-min interval, there are significant random fluctuations in the value of traffic volume in subsequent time intervals, which make further analysis difficult. Random fluctuations do not occur for the most part in the case of traffic volume aggregated to an hour. Hence, the values of traffic volume aggregated to hourly data were analyzed in detail. A daily traffic pattern was used which was a linear combination of two Gaussian functions to describe the variability of traffic volume over the day:

$$
Q(t)=a_{0}+a_{1} \cdot e^{\frac{-\left(t-\mu_{1}\right)^{2}}{2 \cdot \sigma_{1}^{2}}}+a_{2} \cdot e^{\frac{-\left(t-\mu_{2}\right)^{2}}{2 \cdot \sigma_{2}^{2}}}
$$

where:

$Q(t)$ - a daily traffic pattern on working days (from Monday to Friday),

$a_{0}, a_{1}, a_{2}$-parameters of the function representing the traffic volume in the night, morning, and afternoon rush hours, respectively,

$\mu_{1}, \mu_{2}$-normal distribution parameters (expected value),

$\sigma_{1}, \sigma_{2}$-normal distribution parameters (variance).

Parameters of the trend function $Q(t)$, i.e., $a_{0}, a_{1}, a_{2}$ were determined by the least squares method separately for each day of the week and then for each week for each intersection. The Statistica package was used for this purpose. Values of the determination coefficients $R^{2} \in\langle 0.92,0.98\rangle$ were obtained. It can be concluded that the obtained daily traffic patterns are well-suited to the real distribution of traffic volume values. The assessment of the fit of the $Q(t)$ function to the empirical data was made by determining the values of the mean relative errors. They correspond to the mean values of the square errors to the mean value of the measured traffic volume:

$$
\delta=\frac{\sqrt{\frac{1}{n} \sum_{i=1}^{n}\left(Q_{o, i}-Q_{m, i}\right)^{2}}}{\frac{1}{n} \sum_{i=1}^{n} Q_{o, i}} \cdot 100 \%
$$

where:

$\delta$-mean relative error [\%],

$n$-number of observations, 
$Q_{0, i}$ - i-th observed traffic volume [Veh./h],

$Q_{m, i}$ - $i$-th traffic volume determined from the bimodal trend function [Veh./h].

Tables 6 and 7 present the determined values of the parameters of the traffic volume variability function in the day for 2019 and 2020.

(a)

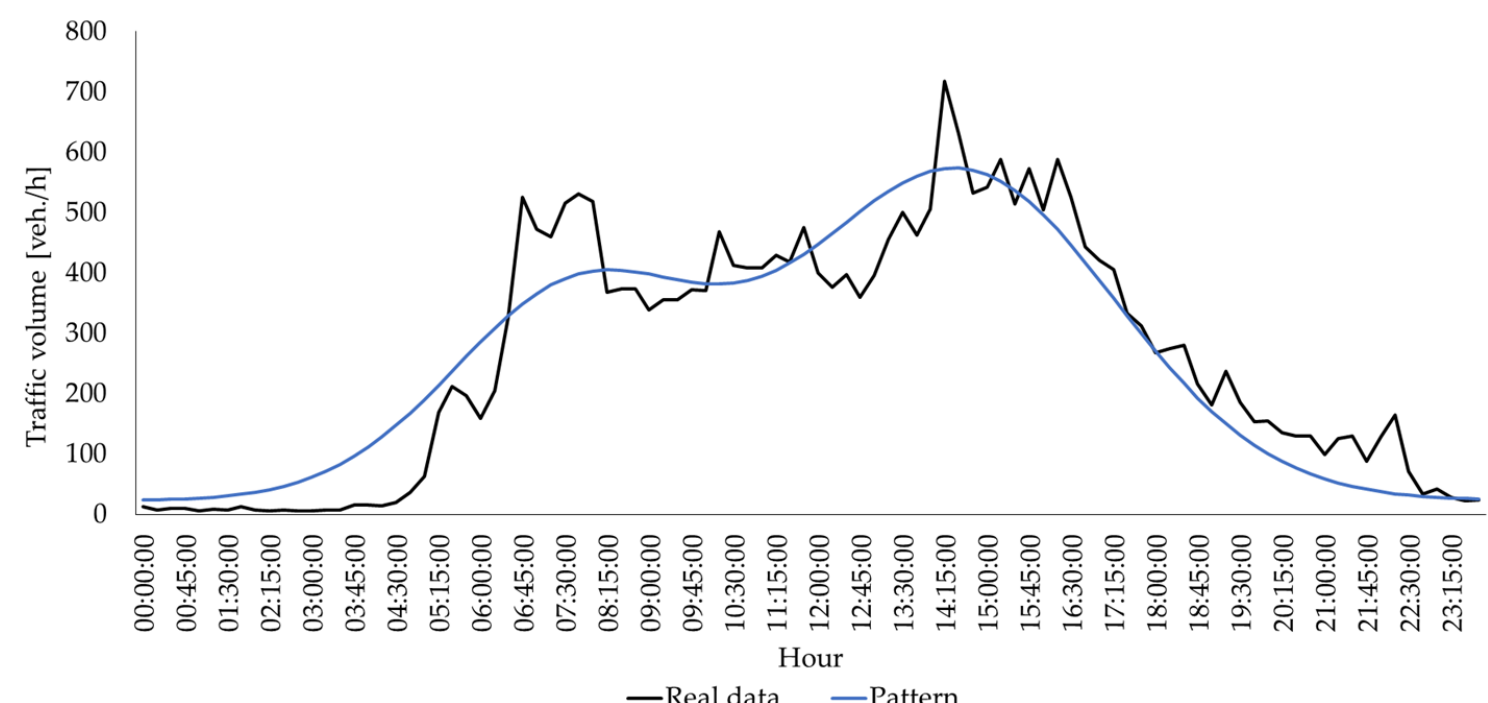

(b)

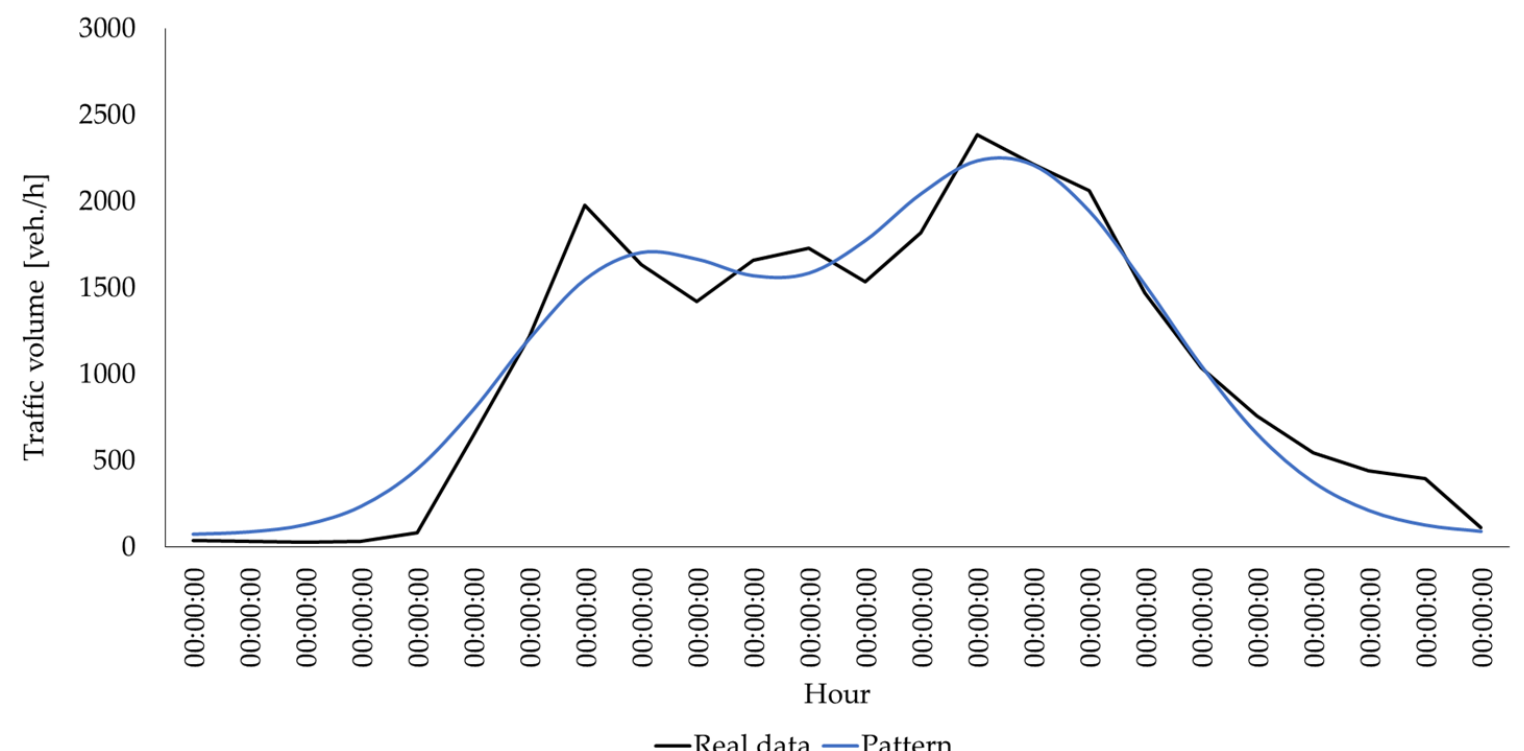

Figure 8. Daily variability of the value of traffic volume in intervals of: (a). fifteen minutes, and (b). hourly for the (eighth) week of 2020 at the Andersa-Okulickiego intersection. 
Table 6. Values of the parameters of the function of a daily traffic pattern on working days in particular weeks for the analyzed intersections in 2019.

\begin{tabular}{|c|c|c|c|c|c|c|c|c|}
\hline \multirow{2}{*}{$\begin{array}{c}\text { Week } \\
\text { Number }\end{array}$} & \multicolumn{8}{|c|}{ Function Parameters $Q(t)$} \\
\hline & $\begin{array}{c}a_{0} \\
{[\text { Veh./h] }}\end{array}$ & $\begin{array}{c}a_{1} \\
{[\text { Veh./h] }}\end{array}$ & $\begin{array}{l}\mu_{1} \\
{[\mathrm{~h}]}\end{array}$ & $\begin{array}{c}\sigma_{1} \\
{[\mathrm{~h}]}\end{array}$ & $\begin{array}{c}a_{2} \\
{[\text { Veh./h] }}\end{array}$ & $\begin{array}{l}\mu_{2} \\
{[\mathrm{~h}]}\end{array}$ & $\begin{array}{c}\sigma_{2} \\
{[\mathrm{~h}]}\end{array}$ & $\begin{array}{c}\delta \\
{[\%]}\end{array}$ \\
\hline \multicolumn{9}{|c|}{ Intersection 1} \\
\hline 8 & 56 & 1502 & $07: 45$ & $02: 16$ & 2166 & $14: 30$ & $02: 47$ & 17.40 \\
\hline 12 & 12 & 1753 & $07: 30$ & 02:17 & 2418 & $15: 15$ & 02:39 & 16.56 \\
\hline 17 & 53 & 1804 & 07:30 & 02:17 & 2424 & $15: 30$ & 02:49 & 16.18 \\
\hline 21 & 17 & 1703 & $07: 45$ & 02:19 & 2311 & $15: 30$ & $02: 45$ & 15.39 \\
\hline 26 & 93 & 1691 & $07: 45$ & $02: 22$ & 2143 & $15: 45$ & $02: 53$ & 16.44 \\
\hline \multicolumn{9}{|c|}{ Intersection 2} \\
\hline 8 & 33 & 1108 & $07: 45$ & 02:21 & 1713 & $15: 00$ & 02:35 & 16.68 \\
\hline 12 & 40 & 1330 & $07: 45$ & $02: 19$ & 1908 & $15: 15$ & $02: 33$ & 16.40 \\
\hline 17 & 35 & 1290 & $07: 45$ & $02: 23$ & 1966 & $15: 30$ & $02: 53$ & 17.41 \\
\hline 21 & 14 & 1349 & $07: 45$ & $02: 18$ & 1977 & $15: 30$ & $02: 40$ & 15.97 \\
\hline 26 & 86 & 1235 & 07:45 & 02:19 & 1802 & $15: 30$ & 02:51 & 16.23 \\
\hline \multicolumn{9}{|c|}{ Intersection 3} \\
\hline 8 & 100 & 1662 & $07: 45$ & $02: 18$ & 2471 & $15: 30$ & 02:41 & 16.58 \\
\hline 12 & 57 & 1949 & $07: 45$ & $02: 22$ & 2795 & $15: 30$ & $02: 45$ & 16.29 \\
\hline 17 & 115 & 1738 & $07: 45$ & $02: 52$ & 2632 & $15: 30$ & $02: 53$ & 17.59 \\
\hline 21 & 32 & 1959 & $07: 45$ & $02: 23$ & 2710 & $15: 30$ & $02: 51$ & 15.56 \\
\hline 26 & 162 & 1657 & $07: 45$ & $02: 23$ & 2376 & $15: 15$ & 02:55 & 17.30 \\
\hline \multicolumn{9}{|c|}{ Intersection 4} \\
\hline 8 & 43 & 1518 & $07: 45$ & $02: 18$ & 2315 & $15: 00$ & $02: 39$ & 17.30 \\
\hline 12 & 19 & 2017 & $07: 45$ & $02: 16$ & 2710 & $15: 30$ & 02:39 & 18.15 \\
\hline 17 & 59 & 1909 & $07: 45$ & $02: 16$ & 2665 & $15: 30$ & $02: 48$ & 17.14 \\
\hline 21 & 11 & 2004 & $07: 45$ & $02: 14$ & 2665 & $15: 30$ & $02: 49$ & 16.45 \\
\hline 26 & 128 & 1780 & $07: 45$ & $02: 18$ & 2454 & $15: 30$ & $02: 53$ & 19.26 \\
\hline \multicolumn{9}{|c|}{ Intersection 5} \\
\hline 8 & 92 & 1206 & $07: 45$ & 02:17 & 1876 & $15: 15$ & 02:35 & 14.42 \\
\hline 12 & 91 & 1435 & $07: 45$ & $02: 18$ & 1961 & $15: 15$ & $02: 39$ & 13.86 \\
\hline 17 & 127 & 1379 & $07: 45$ & $02: 23$ & 1985 & $15: 30$ & $02: 43$ & 15.93 \\
\hline 21 & 86 & 1452 & $07: 45$ & $02: 24$ & 2070 & $15: 30$ & 02:45 & 12.82 \\
\hline 26 & 164 & 1299 & $07: 45$ & 02:21 & 2057 & $15: 15$ & $02: 43$ & 15.70 \\
\hline \multicolumn{9}{|c|}{ Intersection 6} \\
\hline 8 & 300 & 1343 & $07: 15$ & 02:17 & 1382 & $14: 30$ & $02: 32$ & 17.92 \\
\hline 12 & 310 & 1383 & $07: 15$ & $02: 19$ & 1885 & $14: 30$ & $02: 39$ & 17.78 \\
\hline 17 & 230 & 1952 & $07: 45$ & $02: 13$ & 1940 & $14: 45$ & $02: 52$ & 16.41 \\
\hline 21 & 295 & 1451 & $07: 15$ & $02: 15$ & 1941 & $14: 30$ & $02: 51$ & 16.82 \\
\hline 26 & 203 & 2023 & 07:30 & 02:17 & 2002 & $14: 04$ & $02: 47$ & 17.72 \\
\hline \multicolumn{9}{|c|}{ Intersection 7} \\
\hline 8 & 112 & 1669 & $07: 45$ & $02: 19$ & 1562 & $15: 45$ & $02: 47$ & 15.84 \\
\hline 12 & 53 & 1759 & $07: 45$ & $02: 21$ & 2336 & $15: 15$ & $02: 48$ & 14.22 \\
\hline 17 & 172 & 1603 & $07: 45$ & $02: 25$ & 2166 & $15: 15$ & $02: 52$ & 16.31 \\
\hline 21 & 30 & 1653 & $07: 45$ & $02: 27$ & 2228 & $15: 30$ & $02: 55$ & 13.90 \\
\hline 26 & 112 & 1573 & $07: 45$ & $02: 25$ & 2017 & $15: 30$ & $02: 56$ & 14.91 \\
\hline \multicolumn{9}{|c|}{ Intersection 8} \\
\hline 8 & 117 & 1493 & $07: 45$ & 02:17 & 2045 & $15: 00$ & $02: 43$ & 14.31 \\
\hline 12 & 141 & 1596 & $07: 45$ & $02: 21$ & 2201 & $15: 00$ & 02:49 & 13.55 \\
\hline 17 & 102 & 1622 & $07: 45$ & $02: 23$ & 2382 & $15: 00$ & $02: 52$ & 12.07 \\
\hline 21 & 120 & 1515 & $07: 45$ & $02: 25$ & 2106 & $15: 00$ & $02: 52$ & 13.50 \\
\hline 26 & 169 & 1232 & $07: 45$ & $02: 12$ & 2075 & $14: 30$ & $02: 53$ & 14.96 \\
\hline
\end{tabular}


Table 7. Values of the parameters of the function of a daily traffic pattern on working days in particular weeks for the analyzed intersections in 2020.

\begin{tabular}{|c|c|c|c|c|c|c|c|c|}
\hline \multirow{2}{*}{$\begin{array}{c}\text { Week } \\
\text { Number }\end{array}$} & \multicolumn{8}{|c|}{ Function Parameters $Q(t)$} \\
\hline & $\begin{array}{c}a_{0} \\
{[\text { Veh./h] }}\end{array}$ & $\begin{array}{c}a_{1} \\
{[\text { Veh./h] }}\end{array}$ & $\begin{array}{l}\mu_{1} \\
{[\mathrm{~h}]}\end{array}$ & $\begin{array}{c}\sigma_{1} \\
{[\mathrm{~h}]}\end{array}$ & $\begin{array}{c}a_{2} \\
{[\text { Veh./h] }}\end{array}$ & $\begin{array}{l}\mu_{2} \\
{[\mathrm{~h}]}\end{array}$ & $\begin{array}{c}\sigma_{2} \\
{[\mathrm{~h}]}\end{array}$ & $\begin{array}{c}\delta \\
{[\%]}\end{array}$ \\
\hline \multicolumn{9}{|c|}{ Intersection 1} \\
\hline 8 & 71 & 1741 & $07: 15$ & $02: 13$ & 2373 & $14: 45$ & $02: 39$ & 16.94 \\
\hline 12 & 33 & 1166 & $07: 15$ & 02:18 & 1811 & $14: 30$ & 02:38 & 18.53 \\
\hline 17 & 27 & 1201 & $07: 15$ & 02:17 & 1516 & $15: 00$ & $02: 57$ & 20.32 \\
\hline 21 & 83 & 1402 & $07: 45$ & 02:18 & 1976 & $15: 15$ & 02:55 & 16.05 \\
\hline 26 & 61 & 1504 & 07:30 & 02:20 & 2089 & $15: 30$ & $02: 56$ & 16.53 \\
\hline \multicolumn{9}{|c|}{ Intersection 2} \\
\hline 8 & 40 & 1312 & $07: 45$ & 02:15 & 1817 & $15: 00$ & $02: 31$ & 18.19 \\
\hline 12 & 37 & 909 & $07: 45$ & $02: 18$ & 1291 & $14: 45$ & $02: 29$ & 15.10 \\
\hline 17 & 33 & 971 & $07: 45$ & 02:17 & 1094 & $14: 15$ & $02: 45$ & 20.68 \\
\hline 21 & 43 & 1129 & $07: 45$ & $02: 20$ & 1649 & $15: 30$ & $02: 49$ & 16.19 \\
\hline 26 & 60 & 1099 & $07: 45$ & $02: 24$ & 1740 & $15: 30$ & $02: 52$ & 14.96 \\
\hline \multicolumn{9}{|c|}{ Intersection 3} \\
\hline 8 & 155 & 2016 & $07: 45$ & $02: 21$ & 2713 & $15: 45$ & 02:41 & 16.08 \\
\hline 12 & 213 & 1041 & $07: 45$ & $02: 27$ & 1470 & $15: 00$ & $02: 48$ & 12.35 \\
\hline 17 & 277 & 936 & $07: 45$ & $02: 29$ & 1160 & $15: 15$ & $02: 53$ & 15.07 \\
\hline 21 & 262 & 1244 & $07: 45$ & $02: 27$ & 1827 & $15: 15$ & $02: 56$ & 13.19 \\
\hline 26 & 299 & 1344 & $07: 45$ & $02: 24$ & 2004 & $15: 15$ & $02: 57$ & 14.32 \\
\hline \multicolumn{9}{|c|}{ Intersection 4} \\
\hline 8 & 63 & 1935 & $07: 45$ & $02: 15$ & 2496 & $15: 15$ & $02: 37$ & 19.22 \\
\hline 12 & 40 & 1066 & $07: 45$ & 02:18 & 1493 & $14: 45$ & 02:41 & 17.73 \\
\hline 17 & 23 & 1065 & $07: 30$ & $02: 19$ & 1370 & $15: 15$ & $02: 47$ & 17.96 \\
\hline 21 & 56 & 1285 & 07:30 & $02: 21$ & 2301 & $15: 00$ & $02: 48$ & 15.70 \\
\hline 26 & 71 & 1469 & $07: 45$ & $02: 28$ & 2227 & $15: 15$ & $02: 49$ & 16.94 \\
\hline \multicolumn{9}{|c|}{ Intersection 5} \\
\hline 8 & 95 & 1355 & $07: 45$ & $02: 22$ & 1883 & $15: 15$ & 02:41 & 16.51 \\
\hline 12 & 53 & 887 & 07:30 & $02: 27$ & 1250 & $14: 45$ & $02: 48$ & 15.25 \\
\hline 17 & 45 & 897 & 07:30 & $02: 28$ & 1188 & $15: 15$ & $02: 54$ & 16.29 \\
\hline 21 & 69 & 1122 & $07: 45$ & $02: 27$ & 1871 & $15: 15$ & $02: 53$ & 11.33 \\
\hline 26 & 132 & 1233 & $07: 45$ & $02: 36$ & 1766 & $15: 30$ & $02: 47$ & 13.95 \\
\hline \multicolumn{9}{|c|}{ Intersection 6} \\
\hline 8 & 320 & 1392 & $07: 45$ & 02:15 & 1836 & $15: 30$ & 02:32 & 18.87 \\
\hline 12 & 224 & 1043 & 07:00 & $02: 18$ & 1453 & $14: 30$ & $02: 41$ & 17.83 \\
\hline 17 & 219 & 1008 & $07: 30$ & $02: 23$ & 1229 & $15: 15$ & $02: 47$ & 15.50 \\
\hline 21 & 198 & 1141 & $07: 45$ & $02: 27$ & 1744 & $15: 45$ & $02: 51$ & 15.12 \\
\hline 26 & 298 & 1056 & 07:30 & $02: 23$ & 1597 & $15: 00$ & 02:39 & 14.69 \\
\hline \multicolumn{9}{|c|}{ Intersection 7} \\
\hline 8 & 408 & 1619 & $07: 45$ & $02: 17$ & 2100 & $15: 15$ & $02: 36$ & 16.86 \\
\hline 12 & 91 & 968 & $07: 45$ & $02: 21$ & 1328 & $15: 00$ & $02: 41$ & 12.63 \\
\hline 17 & 87 & 1055 & $07: 30$ & $02: 22$ & 1134 & $15: 15$ & $02: 50$ & 15.44 \\
\hline 21 & 126 & 1202 & $07: 45$ & $02: 24$ & 1662 & $15: 15$ & $02: 53$ & 12.25 \\
\hline 26 & 132 & 1286 & $07: 45$ & $02: 27$ & 1729 & $15: 15$ & $02: 54$ & 13.26 \\
\hline \multicolumn{9}{|c|}{ Intersection 8} \\
\hline 8 & 157 & 1569 & $07: 45$ & 02:47 & 2121 & $15: 15$ & 02:47 & 18.68 \\
\hline 12 & 78 & 954 & $07: 45$ & $02: 49$ & 1331 & $15: 00$ & 02:49 & 13.95 \\
\hline 17 & 65 & 1009 & $07: 45$ & $02: 51$ & 1234 & $15: 30$ & $02: 51$ & 14.76 \\
\hline 21 & 92 & 1225 & $07: 45$ & $02: 53$ & 1791 & $15: 30$ & $02: 53$ & 15.41 \\
\hline 26 & 117 & 1165 & $07: 45$ & $02: 56$ & 1832 & $15: 30$ & $02: 56$ & 15.48 \\
\hline
\end{tabular}


For 2019 , the average relative error ranges from $12.07 \%$ to $19.26 \%$, while for 2020 it ranges from $11.33 \%$ to $20.68 \%$ in the analyzed cases. Based on the determined parameters of the bimodal trend function, the following conclusions can be made:

- the traffic volume at night (parameter $a_{0}$ ) in the 8th week is higher in 2020 than in 2019. The 8th week represents the average week of the year before the pandemic period, and, assuming a trend of increasing traffic over time, this is an explainable phenomenon,

- the traffic volume during the night hours in the 12th week of 2020 (which was also the first full lockdown week in Poland) is in most of the analyzed cases lower than the traffic volume in 12th week of 2019. Similar conclusions can be drawn for the 17 th week, which represents the average week in lockdown,

- $\quad$ in the 21st week of 2020 (in the stage of a partial opening of the country's economy), the value of the parameter $a_{0}$ (traffic volume at night) is higher than in 2019 in the majority of cases,

- $\quad$ the traffic volume in the morning rush hours in all cases (except for intersection 6) is higher in 2020 than in 2019 for the average week of the year before the pandemic period,

- for the first full week of lockdown in Poland and the following weeks during the lockdown, the traffic volume during the morning rush hours in all cases is lower in 2020 than in 2019. The traffic volume in the morning rush hours increases in the stage of partial opening of the country's economy and after the reopening of most services while maintaining the required sanitary regime, after the end of the school and academic year (17th and 26th week of 2020), but it does not reach the level close to the morning rush hour value in 2019,

- the traffic volume during the afternoon rush hours in the 8th week is in all cases higher in 2020 than in 2019. On the other hand, the traffic volume in the afternoon rush hours during the lockdown and after the reopening of the country's economy while maintaining the sanitary regime is lower in 2020 than in 2019 (12th, 17th, 21st, and 26th week of the year),

- for the afternoon rush hours $\left(\sigma_{2}\right)$, the variance will take larger values than in the morning rush hours $\left(\sigma_{1}\right)$, which means that the values of the traffic volume in the afternoon rush hours are more varied than in the morning rush hours. This is noticeable for both 2019 and 2020. Moreover, in many cases, the values of the variance for the afternoon rush hours in the lockdown and sanitary regime are higher than in the corresponding weeks of 2019. This confirms a greater variation in the value of traffic volume in the afternoon rush hours in 2020 than in 2019.

Figure 9 shows the functions of the variability of traffic volume on working days in the analyzed weeks of 2019 and 2020. 


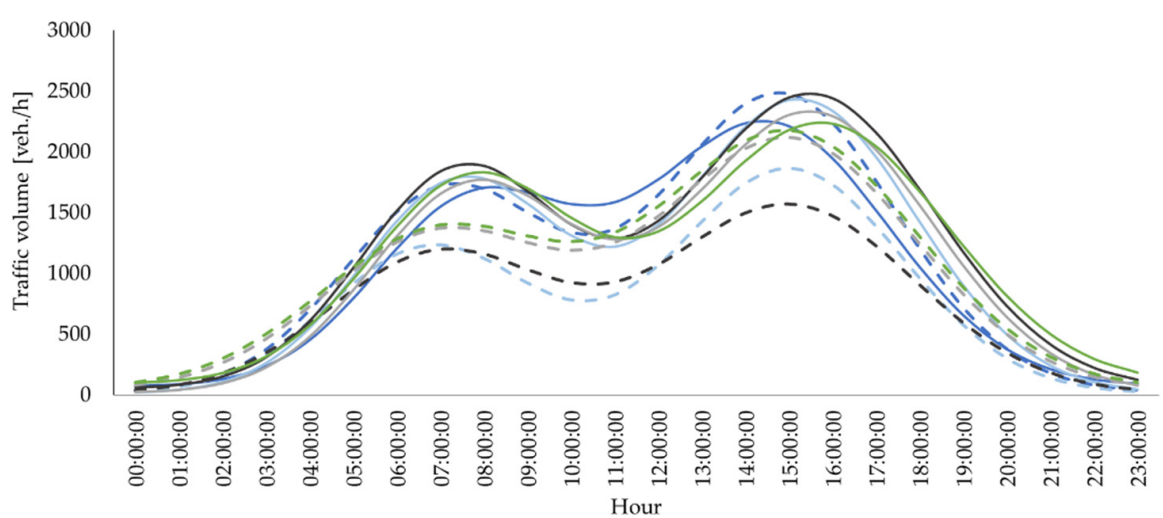

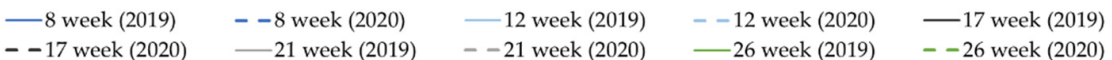

(c)

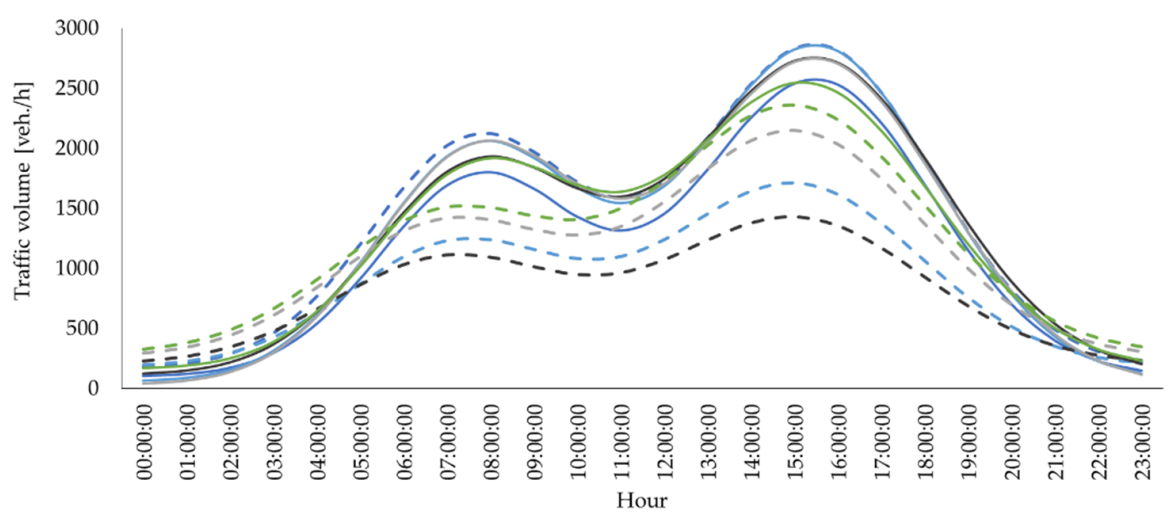

(b)

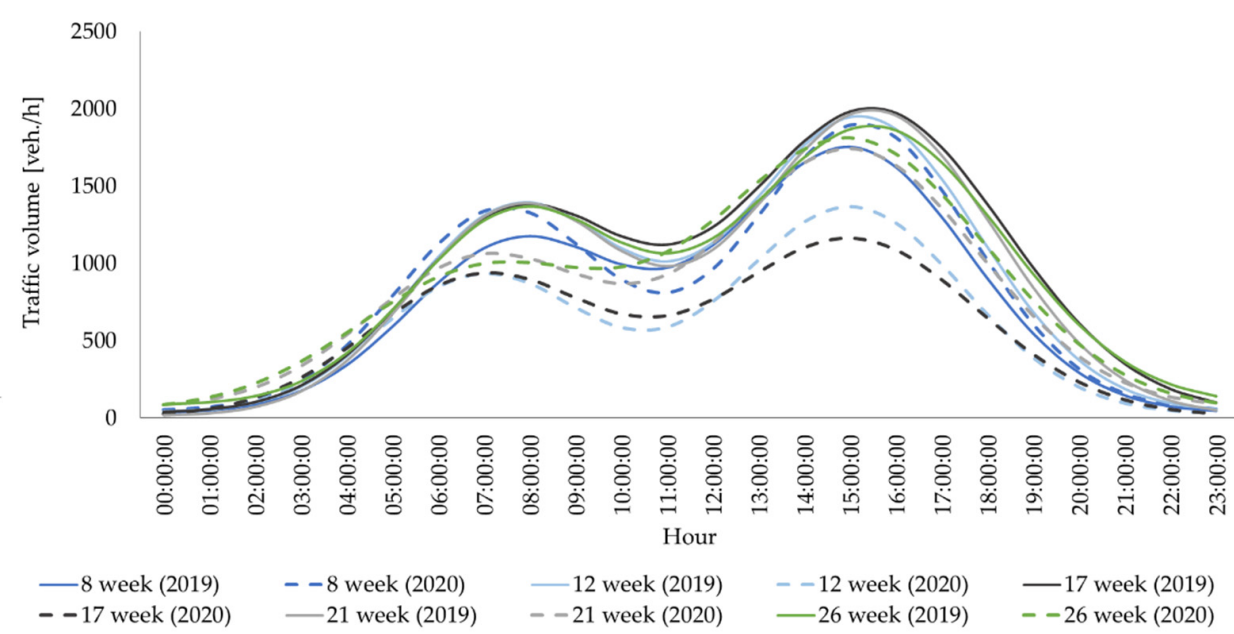

(d)

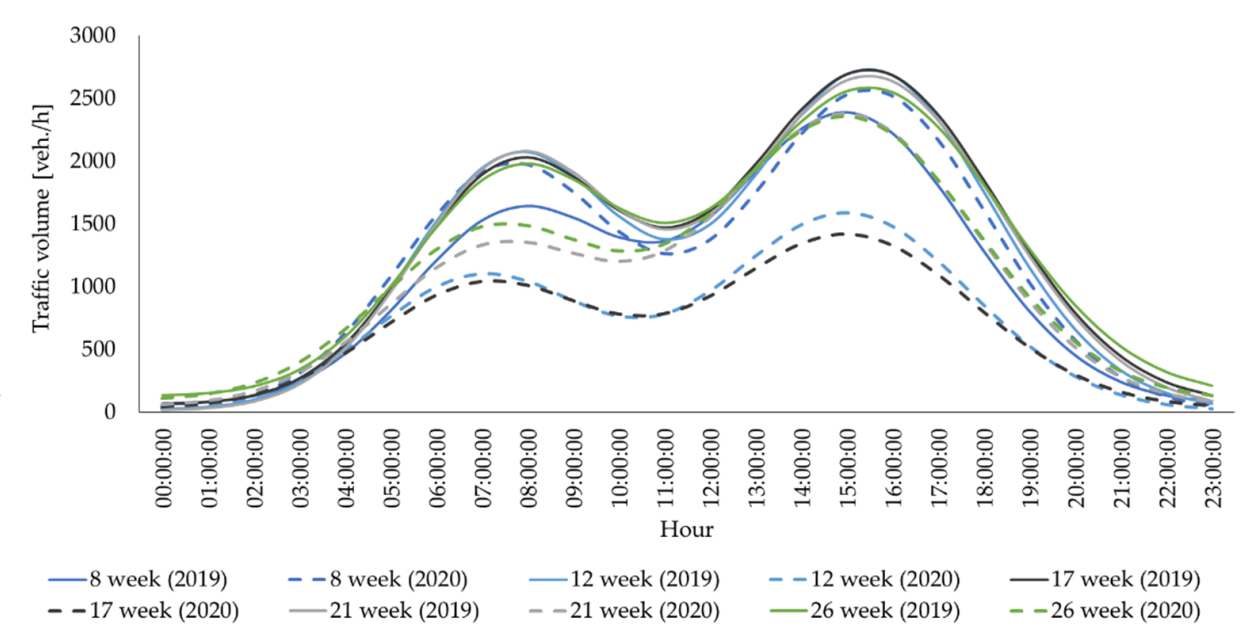

Figure 9. Cont. 
(e)

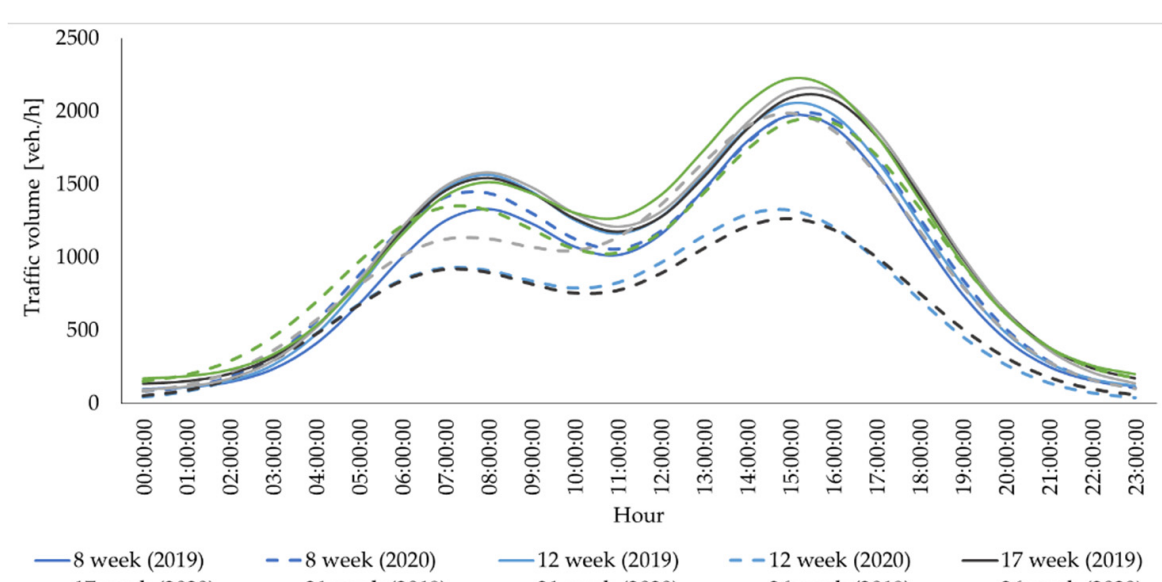

- 8 week (2019)

--8 week $(2020)$
-21 week (2019)

-12 week $(2019)$
--21 week $(2020)$

-26 week (2019)

--26 week $(2020)$

(g)

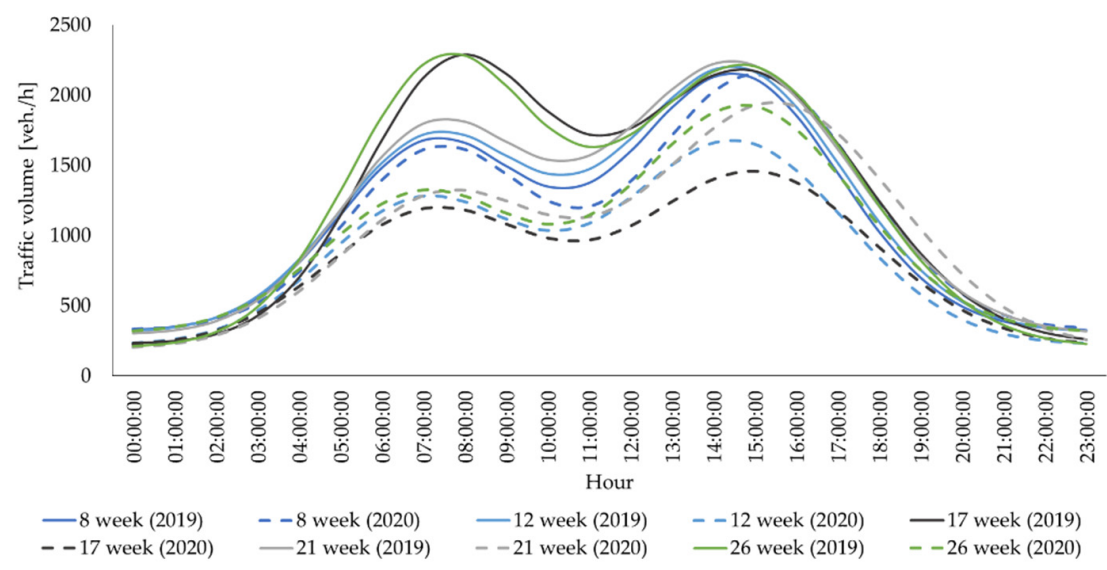

(f)

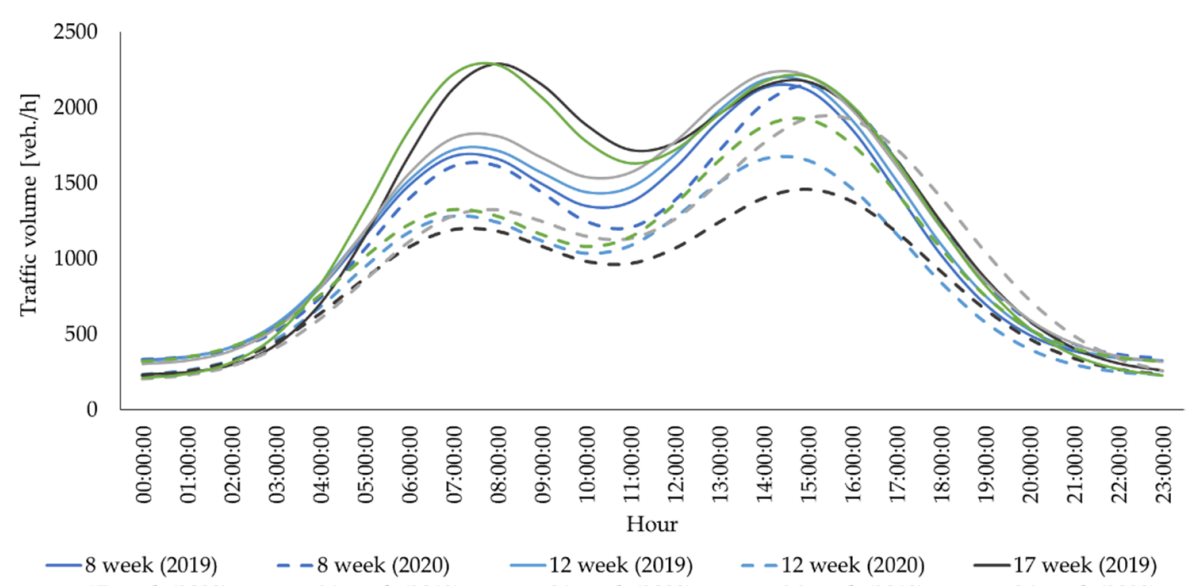

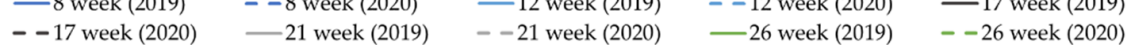

(h)

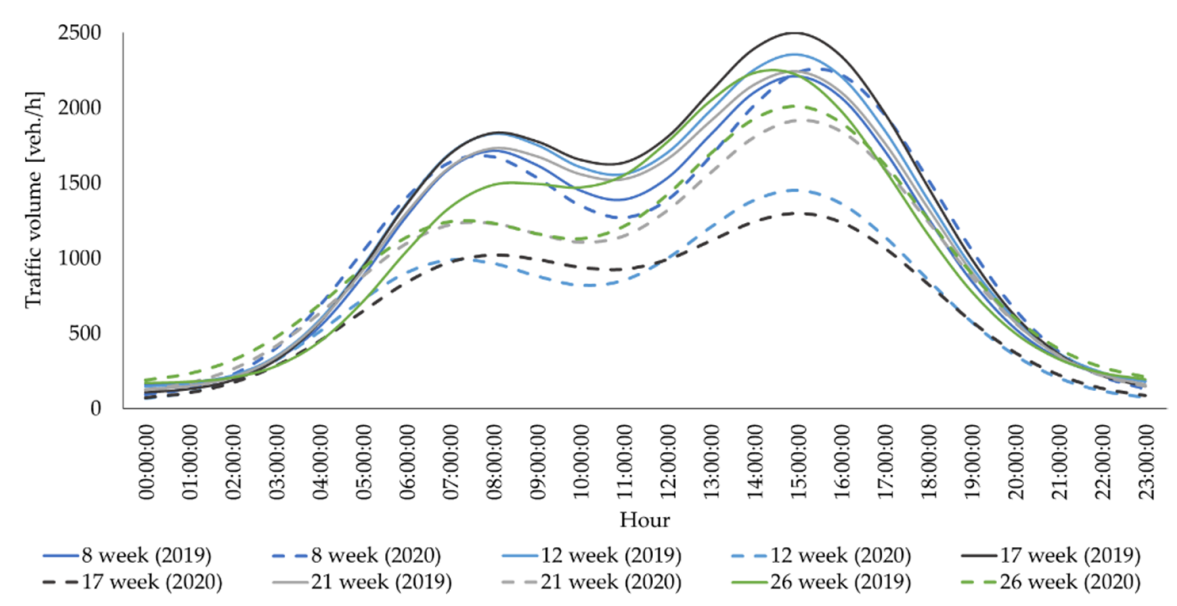

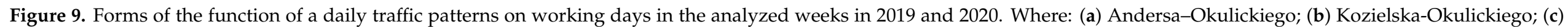

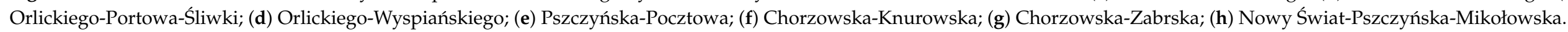




\section{Discussion}

The covid-19 pandemic has strongly changed life, work, recreation, and retail, as well as ways of thinking and approaches to life. Lockdowns, remote working and learning, and other restrictions on movement have influenced people's mobility patterns and reduced traffic congestion in most cities around the world. In Poland, the first wave of the pandemic began on 14 March 2020. Also, a significant reduction in the case of road traffic volume was observed due to the pandemic. The data presented in the article allows us to formulate some relations between the various pandemic regulations and the traffic volume changes caused by each of them:

- the introduction of restrictions in the first days of week 11 of 2020 (i.e., from 12 to 15 March) resulted in fluctuations in traffic volume from $+0.54 \%$ to $-15.60 \%$ (an average decrease by $-6.99 \%$ ) compared to the AADT in 2019,

- the state of epidemic emergency was declared in Poland in the first full week of lockdown (20 March). From this week, significant decreases in traffic volume took place in many Polish cities [50,51]. These decreases ranged from $-23.05 \%$ to $-42.86 \%$ (an average decrease by $-32.10 \%$ ) in the case of the analyzed intersections,

- in the 13th week of 2020, while maintaining the pandemic regulations introduced so far, the decreases in traffic volume were also maintained at a similar level to the previous week, ranging from $-17.69 \%$ to $-43.42 \%$ (an average decrease by $-32.65 \%$ ) compared to AADT in 2019,

- in the 14th week of 2020, the introduction of the next restrictions resulted in a further decrease in traffic volume on the transport network in the range of $-29.49 \%$ to $-46.88 \%$ (an average decrease of $-35.87 \%$ ) compared to AADT in 2019,

- in the following weeks of total lockdown in the country, the decrease in traffic volume remained at a similar level. In the 17th week of 2020, traffic volume slightly increased compared to the previous weeks (an average decrease of $-34.84 \%$ compared to AADT in 2019),

- the resumption of some services and activities in the 19th week of 2020 resulted in a significant increase in the value of traffic volume on the transport network from $-8.33 \%$ to $-29.46 \%$ (an average decrease by $-17.99 \%$ ) compared to AADT in 2019 . This increase is visible in the case of the distribution of total road traffic volume at all analyzed intersections (Figure 5),

- in the 20th week of 2020, borders were opened again (13 May), but it did not cause a significant increase the traffic volume (average decrease in traffic volume by $-17.81 \%$ compared to AADT in 2019),

- in the 21st week of 2020, the value of traffic volume on the transport network increased to the level from $-3.15 \%$ to $-16.41 \%$ (an average decrease by $-10.78 \%$ ) compared to AADT in 2019,

- in the 22nd week of 2020, hotels were opened, but this also did not cause any rapid changes in traffic volume on the transport network compared to the previous week (an average decrease by $-10.47 \%$ compared to AADT in 2019),

- during the summer holiday period (from the 23rd to the 32nd week of 2020), at the analyzed intersections, the highest values of traffic volume can be observed, often comparable (or slightly lower) than the adequate values of traffic volume in 2019,

- the introduction of the yellow zone for the analyzed area in the 32nd week of 2020 resulted in a slight decrease in the value of traffic volume from $-2.91 \%$ to $-19.66 \%$ (an average decrease by $-12.55 \%$ ) compared to AADT in 2019,

- from the 43rd week of 2020, the ban on the operation of so many activities was reflected in a decrease in traffic volume on the transport network. However, the decrease in traffic volume accompanying the second wave of the pandemic was not as significant as it was during the first wave of the pandemic (Figure 6). This decrease ranged from $-5.85 \%$ to $-15.81 \%$ (an average decrease of $-11.55 \%$ ) compared to AADT in 2019,

- in the 44th week, the value of traffic volume slightly decreased from $-6.26 \%$ to $-18.36 \%$ (an average decrease of $-12.19 \%$ ) compared to AADT in 2019. In the 45 th 
week, the value of traffic volume slightly decreased from $-8.56 \%$ to $-22.00 \%$ (an average decrease by $-14.83 \%$ ) compared to AADT in 2019,

- the reduction in mobility in the 46th week of 2020 was reflected in a further decrease in the value of traffic volume from $-15.34 \%$ to $-24.17 \%$ (average decrease by $-18.20 \%$ ) compared to AADT in 2019,

- $\quad$ in the 48 th week of 2020 , a slight, over $4 \%$ increase in the value of traffic volume on the transport network occured. Despite this, a decrease from $-5.92 \%$ to $-20.79 \%$ (an average decrease by $-14.13 \%$ ) compared to AADT in 2019 has been observed.

The greatest decrease in traffic volume took place during the first wave of the pandemic (from the 11th week to 19th week of 2020, i.e., from 9 March to 10 May 2020). At that time, the road traffic variability factor for particular intersections varied from $1.10 \%$ to as much as $-45.70 \%$. During 2020, there were also other decreases in the value of traffic volume below the AADT, which resulted from the winter break, summer holidays, or the second wave of coronavirus that occurred in Poland in the autumn months. These decreases are not as large as they were in the first wave of the pandemic. The obtained results are confirmed in other countries around the world, where the value of traffic volume decreased significantly also due to the pandemic [52]. The large decrease in traffic volume during 2020 was also recorded in France [53]. This resulted from both short-range and long-range population travel stopping following the first wave lockdown by as much as $65 \%$. In Greece, traffic volume decreased by more than $80 \%$ during the most serious period of the pandemic [54]. Also, a 65\% decrease in traffic volume was identified on non-urban roads in Spain compared to the same period in 2019 [55]. In the USA, in Florida, overall state-wide traffic volume decreased by $47.5 \%$ [56]. Meanwhile, a data analysis by Tom Tom of several major European cities has shown that road traffic volume reduced in 2020 in comparison to 2019 [51]:

- from 54\% to 51\% in such cities as Moscow (54\%), Mumbai (53\%), Bogota (53\%), Istanbul (51\%), and Kiev (51\%),

- $\quad$ from $47 \%$ to $25 \%$ in such cities as New Delhi (47\%), Bangkok (44\%), Odessa (44\%), Łódż (42\%), Lima (42\%), Chonquing (41\%), Bucharest (42\%), Tokyo (41\%), Tel Aviv (37\%), Mexico City (36\%), Osaka (35\%), Athens (34\%), Paris (32\%), London (31\%), Berlin (30\%), Sydney (28\%), Rome (27\%), and Luxeburg (25\%),

- from $24 \%$ to $15 \%$ in such cities as Beijing (24\%), Antwerp (24\%), Porto (24\%), Shanghai (22\%), Frankfurt am Main (20\%), Montreal (20\%), Seatle (19\%), Washington (17\%), and Madrid (15\%),

- $\quad$ from $14 \%$ to $7 \%$ in such cities as Quebec (14\%), and Detroit (11\%).

The values of total traffic volume on particular days of the week in particular months in 2020 were lower than in 2019 for all analyzed intersections. The distribution of traffic volume in particular hours of the day is characterized by a smaller hourly dispersion per day than in the case of 2020 at all intersections. Moreover, in 2020, the morning and afternoon rush hours show a greater flattening than in 2019. In 2019, the morning rush hours were from 06:00 to 08:00. In turn, the afternoon rush hours were from 14:00 to 17:00. In 2020, until the 12th week, the morning and afternoon rush hours at the analyzed intersections occurred at the same hours as in 2019. On the other hand, from the 12th week of 2020, the morning rush hours were between 04:00 and 06:00, and the afternoon rush hours after the 12th week 12 of 2020 were between 13:00 and 16:00. Moreover, for each intersection in each month of the year (except for February), the distribution of traffic in 2020 is characterized by a greater blurring during the day than the distribution in 2019. In addition, there is a different daily distribution of traffic volume in April 2020. They are characterized by significantly lower hourly values of traffic volume than in April 2019 or in other months of the year. In the case of 2019, in particular months of the year, the morning and afternoon rush hours at each of the analyzed intersections occurred at similar hours of the day. This regularity can no longer be observed in 2020.

AADT in 2020 was as much as 19\% lower than AADT in 2019. In 2019, the traffic volume in February, July, and August was lower than the AADT value, because in these 
months in Poland there are winter holidays (February) and summer holidays (July and August). The lowest values of traffic volume were recorded in March and April in the case of 2020. Traffic volume is indeed a random variable, the value of which is influenced by many factors, but in the analyzed case the main determinant of low traffic volume in the above-mentioned months was the first wave of the covid-19 pandemic.

The main limitation of the presented results is the lack of analysis for all city intersections and all cities in Poland. The research only included analysis of the variability of the values of traffic volume in 2019 and 2020 at selected intersections located in Gliwice (Poland).

Moreover, the covid-19 pandemic will undoubtedly change many aspects of people's lives, including travel behavior, as well as changes in traffic patterns and modal split. The current results of research on the effects of the covid-19 epidemic in this area suggest that there has been a significant reduction in human mobility and a significant change in travel patterns [57-59].

Nowadays, traveling using public transport can result in the rapid spread of the pandemic, because they are popular in populous middle-income and high-income cities and very often serve as the principal method for a trip for many people in the world. The human infection risk could be extremely high due to the length of the exposure time window, transmission route, and structural characteristics during travel or work. Hence, in the literature on the subject are works on the proposal of long-term effective prevention and control measures proposed for public transport facilities [60,61]. In ation, some research works predict that a post-covid-19 city could experience a sustained decrease in demand for commuting transport due to a combination of durable economic crisis and changing work habits [62-65]. There may be a change in behavior especially toward crowded spaces and public transport as well as a change in a previous travel pattern towards unsustainable mobility. Research works in the literature on the subject have attempted to model mobility choice in commuting to work in large cities after covid-19 [66].

In paper [67], with the use of an online questionnaire, individual mobility patterns were examined for all means of transport (self-driving car, business car, bus, tram, metro, train, plane, foot, bicycle, motorcycle) before and during the restrictions adopted in ten countries of the world, i.e., Australia, USA, Italy, Norway, China, Brazil, Iran, India, Ghana, and South Africa. The results confirmed the existence of huge disruptions in commuting and non-work travel. In addition, results showed a significant reduction in the frequency of all types of travel and the use of all modes of transport. Moreover, planes and buses are perceived as the riskiest modes of transport in terms of the potential spread of the virus, resulting in very large modal shifts (avoiding public transport in favor of private means of transport). In addition, socio-economic inequalities and the incidence of covid-19 per 100,000 inhabitants (and especially the number of deaths) are strongly correlated according to the results from all the countries where research was conducted. Income inequalities also affect the choice of means of transport. These conclusions can guide in planning post-covid-19 transport development strategies.

Subsequent studies [68] also confirm the existence of the impact of both governmentimposed and self-imposed restrictions on travel mobility. The research results show that the epidemic influenced different socio-demographic groups in different ways. On average, in all age groups studied, travel time was reduced by $66 \%$.

On the other hand, research on mobility behavior conducted in Switzerland (based on GPS tracking and online surveys) confirmed a reduction by about $60 \%$ of the average daily distance traveled and a simultaneous decrease of over $90 \%$ in the use of public transport [69]. The share of trips made by bicycle increased at the same time. Research conducted in Poland for the city of Gdańsk also confirmed that the epidemic phenomenon had a significant impact on mobility. In addition, the results indicate that the pandemic influenced the sense of security and psychological comfort of public transport users, which in turn led to the avoidance of traveling by this form of transport. Over $90 \%$ of the respondents gave up or limited the use of public transport according to the survey 
results. However, almost $75 \%$ of them declare that they will return to using public means of transport after the epidemic situation has stabilized [70]. The results of these studies indicate the need for proper development of transport policy after the end of the pandemic, which should focus on improving the perception and ensuring an appropriate image of public transport. Otherwise, it may mean a long-term decline in the number of passengers using the means of public transport. Moreover, covid-19 presents both a challenge and an opportunity to develop new approaches and policies for more sustainable urban transport.

The problem of the strong negative impact of the covid-19 pandemic on journeys made with the use of public transport was the subject of many other scientific works [71-73]. These works indicate that the vast majority of users of public mass transport changed the means of transport to private cars and various forms of non-motorized travel due to the covid-19 pandemic.

The literature on the subject also includes studies on the mobility of rural residents during the period of legal restrictions aimed at stopping the spread of the virus. Research results [74] indicate that $62.6 \%$ of respondents practically did not change their mobile behavior due to the covid-19 pandemic. However, almost a third of all planned trips were not made. There has been a modal shift towards the limitation of bus travel and an increase in bicycle travel. The proportion of foot travel remained unchanged.

\section{Conclusions}

This article analyzes the variability of the values of traffic volume in 2019 and 2020 at selected intersections located in Gliwice, Poland. The following conclusions can be made based on the analyses presented in the article:

- reduction in road traffic volumes during the covid-19 pandemic in Poland is similar to many other countries,

- the different shape and duration of afternoon peaks and morning peaks is the same for 2019 and 2020 but radical changes were noted,

- $\quad$ existing demand patterns are not useful to describe the situation in healthcare emergencies or settings in which heavy and long traffic restrictions are in place due to a motivation that radically changes people's travel routines,

- $\quad$ research on new demand models capable of understanding the changed scenario (with increased use of work-at-home, remote meetings, and distance learning) is needed. Policy makers shall steer this discussion both at the national and EU research project levels.

Continuous measurements of road traffic on the transport network allow us to describe the characteristics of traffic fluctuations, growth, regularity, etc. Systematic analyses allow the obtaining of typical daily, weekly, monthly and annual profiles depending on the traffic characteristics. The daily traffic patterns presented in the article allowed us to indicate both the similarities and differences in daily distributions. After further improvement, these daily traffic patterns may be useful for traffic management in situations of dynamic changes in road traffic volume, assessment of capacity and traffic conditions, and assessment of the impact of roads on the natural environment. The obtained results in this way may constitute the basis for decisions in the field of planning operational and strategic activities. This will allow for improved traffic management in the city and manage subsequent stages of a pandemic or crisis.

Author Contributions: Conceptualization, E.M.; methodology, E.M.; software, A.K.; validation, E.M., and A.K.; formal analysis, E.M.; investigation, A.K.; resources, A.K.; data curation, A.K.; writingoriginal draft preparation, A.K., and E.M.; writing-review and editing, E.M.; visualization, A.K.; supervision, E.M.; project administration, E.M.; funding acquisition, E.M. All authors have read and agreed to the published version of the manuscript.

Funding: Publication supported under the Rector's pro-quality grant. Silesian University of Technology, grant number 12/040/RGJ21/0039.

Institutional Review Board Statement: Not applicable. 
Informed Consent Statement: Not applicable.

Data Availability Statement: The data presented in this study are available on request from the corresponding author.

Acknowledgments: The authors wish to acknowledge The Traffic Management Center in the City of Gliwice for providing access to data for research and analysis purposes as well as for their contributions to the understanding of the system.

Conflicts of Interest: The authors declare no conflict of interest.

\section{References}

1. National Research Council (U.S.); Transportation Research Board. High Capacity Manual 2010 (HCM 2010); Transportation Research Board: Washington, DC, USA, 2010.

2. Macioszek, E. Changes in Values of Traffic Volume-Case Study Based on General Traffic Measurements in Opolskie Voivodeship (Poland). In Directions of Development of Transport Networks and Traffic Engineering. Lecture Notes in Networks and Systems; Macioszek, E., Sierpiński, G., Eds.; Springer International Publishing: Cham, Switzerland, 2019; Volume 51, pp. 66-76.

3. Macioszek, E. The Passenger Car Equivalent Factors for Heavy Vehicles on Turbo Roundabouts. Front. Built Environ. Sect. Transp. Transit Syst. 2019, 5, 1-13. [CrossRef]

4. Hołuj, A.; Frączek, J. The importance of the measurements and analysis of vehicle traffic volume for designing road infrastructure. A case study of Bysina. Infrastruct. Ecol. Rural Area 2015, 4, 1485-1495. [CrossRef]

5. Tettamanti, T.; Horvath, M.Y.; Varga, I. Road traffic measurement and related data fusion methodology for traffic estimation. Transp. Telecommun. 2014, 15, 269-279. [CrossRef]

6. Tong, C.O.; Hung, W.T.; Lam, H.K.W.; Lo, H.K.; Lo, H.P.; Wong, S.C.; Yang, W.H. A new survey methodology for the annual traffic census in Hong Kong. Traffic Eng. Control 2003, 44, 214-218.

7. Lee, S.C. Road traffic monitoring in Hong Kong. In Second International Conference on Road Traffic Monitoring; IET: London, UK, 1989.

8. Handel, P.; Ohlsson, J.; Skog, I.; Nygren, E. Smartphone-based measurement systems for vehicle traffic monitoring and usagebased insurance. IEEE Syst. J. 2014, 8, 1238-1248. [CrossRef]

9. Jacyna, M.; Wasiak, M.; Lewczuk, K.; Kłodawski, M. Simulation model of transport system of Poland as a tool for developing sustainable transport. Arch. Transp. 2014, 31, 23-35. [CrossRef]

10. Jacyna-Gołda, I.; Żak, J.; Gołębiowski, P. Models of traffic flow distribution for various scenarios of the development of proecological transport system. Arch. Transp. 2014, 32, 17-28. [CrossRef]

11. Cieśla, M.; Sobota, A.; Jacyna, M. Multi-Criteria Decision Making Process in Metropolitan Transport Means Selection Based on the Sharing Mobility Idea. Sustainability 2020, 12, 7231. [CrossRef]

12. Macioszek, E. Analysis of driver behaviour at roundabouts in Tokyo and the Tokyo surroundings. In Modern Traffic Engineering in the System Approach to the Development of Traffic Networks. In Advances in Intelligent Systems and Computing; Macioszek, E., Sierpiński, G., Eds.; Springer International Publishing, Springer Nature: Cham, Switzerland, 2020; Volume 1083, pp. $216-227$.

13. Szczuraszek, T.; Macioszek, E. Analysis of time intervals distribution between vehicles on the roadway around central Island of small roundabouts. Roads Bridges 2010, 9, 877-899.

14. Fu, M.; Kelly, J.A.; Clinch, J.P. Estimating annual average daily traffic and transport emissions for a national road network: A bottom-up metodology for both nationally-aggregated and spatially-disaggregated results. J. Transp. Geogr. 2017, 58, 186-195. [CrossRef]

15. Bąkowski, A.; Dekys, V.; Radziszewski, L.; Skrobacki, Z.; Świetlik, P. Estimation of uncertainty and variability of urban traffic volume measurements in Kielce. In Proceedings of the 2018 XI International Science-Technical Conference Automotive Safety, Žastá, Slovakia, 18-20 April 2018. [CrossRef]

16. Jacyna, M.; Wasiak, M. Data Exploration for Determining the Parameters of Volume-Delay Function for Sections in the Traffic Models for Heavily Urbanized Areas. In Proceedings of the 20th International Scientific Conference Transport Means, Juodkrante, Lithuania, 5-7 October 2016; Technologija: Kaunas, Lithuania, 2016; pp. 866-871.

17. Macioszek, E. Relationship between Vehicle Stream in the Circular Roadway of a One-Lane Roundabout and Traffic Volume on the Roundabout at Peak Hour. In Transport Systems Telematic. Communications in Computer and Information Science; Mikulski, J., Ed.; Springer: Berlin/Heidelberg, Germany, 2014; Volume 471, pp. 110-119.

18. ACT of 2 March 2020 on Special Solutions Related to the Prevention, Prevention and Combating of COVID-19, Other Infectious Diseases and Emergencies Caused by Them. Available online: https://isap.sejm.gov.pl/isap.nsf/DocDetails.xsp?id=WDU20200 000374 (accessed on 2 March 2020).

19. Regulation of the Minister of National Education of 20 March 2020 on Special Solutions in the Period of Temporary Limitation of the Functioning of Education System Units in Connection with the Prevention, Counteraction and Combating COVID-19. Available online: https:/ /isap.sejm.gov.pl/isap.nsf/DocDetails.xsp?id=WDU20200000493 (accessed on 20 March 2020). 
20. Regulation of the Council of Ministers of 31 March 2020 on the Establishment of Certain Restrictions, Orders and Prohibitions in Connection with an Epidemic. Available online: https://isap.sejm.gov.pl/isap.nsf/DocDetails.xsp?id=WDU20200000566 (accessed on 31 March 2020).

21. Regulation of the Council of Ministers of 10 April 2020 on the Establishment of Certain Restrictions, Orders and Prohibitions in Connection with an Epidemic. Available online: https://isap.sejm.gov.pl/isap.nsf/DocDetails.xsp?id=WDU20200000658 (accessed on 10 April 2020).

22. Regulation of the Council of Ministers of 19 April 2020 on the Establishment of Certain Restrictions, Orders and Prohibitions in Connection with an Epidemic. Available online: https://isap.sejm.gov.pl/isap.nsf/DocDetails.xsp?id=WDU20200000697 (accessed on 19 April 2020).

23. Regulation of the Council of Ministers of 2 May 2020 on the Establishment of Certain Restrictions, Orders and Prohibitions in Connection with an Epidemic. Available online: http://isap.sejm.gov.pl/isap.nsf/DocDetails.xsp?id=WDU20200000792 (accessed on 2 May 2020).

24. Regulation of the Council of Ministers of 16 May 2020 on the Establishment of Certain Restrictions, Orders and Prohibitions in Connection with an Epidemic. Available online: http://isap.sejm.gov.pl/isap.nsf/DocDetails.xsp?id=WDU20200000878 (accessed on 16 May 2020).

25. Regulation of the Council of Ministers of 5 June 2020 Amending the Regulation on the Establishment of Certain Restrictions, Orders and Prohibitions in Relation to an Epidemic. Available online: https://isap.sejm.gov.pl/isap.nsf/DocDetails.xsp?id= WDU20200001006 (accessed on 5 June 2020).

26. Service of the Republic of Poland. Available online: https:/ / www.gov.pl/web/koronawirus (accessed on 31 December 2020).

27. Shi, Z.; Fang, Y. Temporal relationship putbound traffic from Wuhan and the 2019 coronavirus disease (COVID-19) incidence in China. MedRxiv 2020. [CrossRef]

28. Tanveer, H.; Balz, T.; Cigna, F.; Tapete, D. Monitoring 2011-2020 traffic patterns in Wuhan (China) with COSMO-SkyMed SAR Admist the 7th CISM military world games and COVID-19 outbreak. Remote Sens. 2020, 12, 1636. [CrossRef]

29. Mendoza, D.L.; Benney, T.M.; Ganguli, R.; Pothina, R.; Krick, B.; Pirozzi, C.S.; Crosman, E.T.; Zhang, Y. Understanding the relationship between social distancing policies, traffic volume, air quality, and the prevellence of COVID-19 outcomes in urban neighborhoods. Phys. Soc. 2020, 1-34. Available online: https://arxiv.org/abs/2008.01828 (accessed on 20 July 2020). [CrossRef]

30. Zhiyong, C.; Zhu, M.; Wang, S.; Wang, P.; Zhou, Y.; Cao, Q.; Kopca, C.; Wang, Y. Traffic performance score for measuring the impact of COVID-19 on urban mobility. Phys. Soc. 2020, 1-13. Available online: https:/ /arxiv.org/abs/2007.00648 (accessed on 10 July 2020).

31. Aletta, F.; Brinchi, S.; Carrese, S.; Gemma, A.; Guattari, C.; Mannini, L.; Patella, M. Analysis urban traffic volumes and mapping noise emissions in Rome (Italy) in the context of containment measures for the COVID-19 disease. Noise Mapp. 2020, 7, 114-122. [CrossRef]

32. Stavrinosa, D.; McManusa, B.; Mruga, S.; Heb, H.; Greshama, B.; Albrighta, M.G.; Svancaraa, A.M.; Whittingtona, C.; Underhilla, A.; Whitea, D.M. Adolescent driving behavior before and during restrictions related to COVID-19. Accid. Anal. Prev. 2020, 144, 1-6. [CrossRef] [PubMed]

33. Open Street Map. Available online: https:/ / www.openstreetmap.org/ (accessed on 1 May 2020).

34. Lana, I.; Olabarrieta, I.; Velez, M.; Del Ser, J. On the imputation of missing data for road traffic forecasting: New insights and novel techniques. Transp. Res. Part C 2018, 90, 18-33. [CrossRef]

35. Boquet, G.; Morell, A.; Serrano, J.; Vicario, J.L. A variational autoencoder solution for road traffic forecasting systems: Missing data imputation, dimension reduction, model selection and anomaly detection. Transp. Res. Part C 2020, 115, 1-18. [CrossRef]

36. Tian, Y.; Zhang, K.; Li, J.; Lin, X.; Yang, B. LSTM-based traffic flow prediction with missing data. Neurocomputing 2018, 318, 297-305. [CrossRef]

37. Holt, C.C. Forecasting seasonals and trends by exponentially weighted moving averages. Int. J. Forecast. 2004, 20, 5-10. [CrossRef]

38. Faber, N.M. Estimating the uncertainty in estimates of root mean square error of prediction: Application to determining the size of an adequate test set in multivariate calibration. Chemom. Intell. Lab. Syst. 1999, 79-89. [CrossRef]

39. Chang, Y.; Wang, S.; Zhou, Y.; Wang, L.; Wang, F. A novel method of evaluating highway traffic prosperity based on nighttime light remote sensing. Remote Sens. 2020, 12, 102. [CrossRef]

40. Sahar, S.M.; Pradhan, B. Challenges and limitations of earthquake-induced buolding damage mapping techniques using remote sensing images-A systematic review. Geocarto Int. 2021. [CrossRef]

41. Chen, Y.; Qin, R.; Zhang, G.; Albanwan, H. Spatial temporal analysis of traffic patterns during the covid-19 epidemic by vehicle detection using planet remote-sensing satellite images. Remote Sens. 2021, 13, 208. [CrossRef]

42. Sakai, K.; Seo, T.; Fuse, T. Traffic density estimation method from small satellite imaginery: Towards frequent remote sensing of car traffic. In Proceedings of the 2019 IEEE Intelligent Transportation Systems Conference (ITSC), Auckland, New Zealand, 27-30 October 2019. [CrossRef]

43. Hoogendoorn, S.P.; van Zuylen, H.J.; Schreuder, M.; Gorte, B.; Vosselman, G. Microscopic traffic data collection by remote sensing. Transp. Res. Rec. J. Transp. Res. Board 2003, 1855. [CrossRef]

44. Elshorbany, Y.F.; Kapper, H.C.; Ziemke, J.R.; Parr, S.A. The status of air quality in the United States during the covid-19 pandemic: A remote sensing perspective. Remote Sens. 2021, 13, 369. [CrossRef] 
45. Wemegah, T.D.; Zhu, S. Big Data Challenges in Transportation: A Case Study of Traffic Volume Count from Massive Radio Frequency Identification (FRID) Data. 2017 International Conference on the Frontiers and Advances in Data Science. IEEE Xplore 2018. Available online: https://ieeexplore.ieee.org/abstract/document/8253194 (accessed on 11 May 2020). [CrossRef]

46. Keay, K.; Simmonds, I. The association of rainfall and other weather variables with road traffic volume in Melnnourne, Australia. Accid. Anal. Prev. 2005, 37, 109-124. [CrossRef]

47. Gratani, L.; Varone, L. Daily and seasonal variation of $\mathrm{CO}_{2}$ in the city of Rome in relationship with the traffic volume. Atmos. Environ. 2005, 39, 2619-2624. [CrossRef]

48. Lonati, G.; Cernuschi, M.G. The role of traffic emissions from weekends' and weekdays' fine PM data in Milan. Atmos. Environ. 2006, 40, 5998-6011. [CrossRef]

49. General Directorate for National Roads and Motorways in Poland: Requirements, Assumptions and Recommendations for Traffic Analyzes and Forecasts. Available online: https:/ /www.gddkia.gov.pl/pl/992/zalozenia-do-prognoz-ruchu (accessed on 12 May 2020).

50. Smolarski, M. Restrictions on Regional Passenger Transport during Epidemiological Threat (Covid-19)—An Example of the Lower Silesian Voivodship in Poland. Available online: https:/ /www.ejournals.eu/PKGKPTG/2020/23(2)/art/18147/ (accessed on 21 May 2021).

51. Tomtom Traffic Index. Available online: https:/ /www.tomtom.com/en_gb/traffic-index/ranking/ (accessed on 31 January 2021).

52. Vingilis, E.; Beirness, D.; Boase, P.; Byrne, P.; Johnson, J.; Jonah, B.; Mann, R.E.; Rapoport, M.J.; Seeley, J.; Wickens, C.M.; et al. Coronavirus disease 2019: What could be the effects on road safety? Accid. Anal. Prev. 2020, 144, 1-6. [CrossRef] [PubMed]

53. Pullano, G.; Valdano, E.; Scarpa, N.; Rubrichi, S.; Colizza, V. Evaluating the effect of demographic factors, socioeconomic factors, and risk aversion on mobility during the COVID-19 epidemic in France under lockdown: A population-based study. Lancet Digit. Health 2020, 2, 638-649. [CrossRef]

54. Katrakazas, C.; Michelaraki, E.; Sekadakis, M.; Yannis, G. A descriptive analysis of the effect of the COVID-19 pandemic on driving behavior and road safety. Transp. Res. Interdiscip. Perspect. 2020, 7, 1-19. [CrossRef]

55. European Transport Safety Council. COVID-19: Cities Adapting Road Infrastructure and Speed Limits to Enable Safer Cycling and Walking. Available online: https:/ / etsc.eu/covid-19-huge-drop-in-traffic-in-europe-but-impact-on-road-deaths-unclear/ (accessed on 30 December 2020).

56. Parr, S.; Wolshon, B.; Renne, J.; Murray-Tuite, P.; Kim, K. Traffic impacts of the COVID-19 pandemic: Statewide analysis of social separation and activity restriction. Nat. Hazards Rev. 2020, 21, 1-10. [CrossRef]

57. Atchison, C.J.; Bowman, L.; Vrinten, C.; Redd, R.; Pristera, P.; Eaton, J.W.; Ward, H. Perceptions and Behavioural Responses of the General Public during the Covid-19 Pandemic: A Cross-Sectional Survey of UK Adults. 2020. Available online: https: //www.medrxiv.org/content/10.1101/2020.04.01.20050039v1.full-text (accessed on 1 May 2021).

58. Engle, S.; Stromme, J.; Zhou, A. Staying at Home: The Mobility Effects of Covid-19. Available online: https://voxeu.org/article/ staying-home-mobility-effects-covid-19 (accessed on 1 May 2021).

59. Klein, B.; Larock, T.; Mccabe, S.; Torres, L.; Privitera, F.; Lake, B.; Kraemer, M.U.G.; Brownstein, J.S.; Lazer, D.; Eliassi-Rad, T.; et al. Assessing Changes in Commuting and Individual Mobility in Major Metropolitan Areas in the United States during the COVID-19 Outbreak. 2020. Available online: https://www.networkscienceinstitute.org/publications/assessing-changes-incommuting-and-individual-mobility-in-major-metropolitan-areas-in-the-united-states-during-the-covid-19-outbreak (accessed on 1 May 2021).

60. Shen, J.; Duan, H.; Zhang, B.; Wang, J.; Ji, J.S.; Wang, J.; Pan, L.; Wang, X.; Zhao, K.; Ying, B.; et al. Prevention and control of COVID-19 in public transportation: Experience from China. Environ. Pollut. 2020, 266, 1-5. [CrossRef] [PubMed]

61. Gutierrez, A.; Miravet, D.; Domenech, A. COVID-19 and urban transport services: Emerging challenges and research agenda. Cities Health 2020, 1-4. [CrossRef]

62. Koehl, A. Urban transport and COVID-19: Challenges and prospects in low- and middle-income countries. Cities Health 2020, 1-6. [CrossRef]

63. Hynes, M.; Malone, P. The Utility of Public Transport in Ireland: Post COVID-19 Lockdown Beyond. Public Policy. 2020. Available online: http:/ / publicpolicy.ie/papers / the-utility-of-public-transport-in-ireland-post-covid-19-lockdown-and-beyond/ (accessed on 1 August 2020).

64. Singh, V.; Gupta, K.; Agarwal, A.; Chakrabarty, N. Psychological Impacts on the Travel Behavior Post-COVID-19; Indian Institute of Technology Roorkee, 2020; Available online: http:/ / faculty.iitr.ac.in/ \{\}amitfce/publications.html (accessed on 1 July 2020).

65. Hu, Y.; Barbour, W.; Samaranayake, S.; Work, D. Impack of Covid-19 mode shift on road traffic. Phys. Soc. 2020, 1-14. Available online: https: / / arxiv.org/abs/2005.01610 (accessed on 10 May 2020).

66. Moslem, S.; Campisi, T.; Szmelter-Jarosz, A.; Duleba, S.; Nahiduzzaman, K.; Tesoriere, G. Best-Worst Method for modelling mobility choice after COVID-19: Evidence from Italy. Sustainability 2020, 12, 6824. [CrossRef]

67. Barbieri, D.M.; Lou, B.; Passavanti, M.; Hui, C.; Hoff, I.; Lessa, D.A.; Sikka, G.; Chang, K.; Gupta, A.; Fang, K.; et al. Impact of covid-19 pandemic on mobility in ten countries and associated perceived risk for all transport modes. PLoS ONE 2021, 16, e245886. [CrossRef]

68. Borkowski, P.; Jażdżewska-Gutta, M.; Szmelter-Jarosz, A. Lockdowned: Everyday mobility changes in response to covid-19. J. Transp. Geogr. 2021, 90, 1-13. [CrossRef] 
69. Molloy, J.; Schatzmann, T.; Schoeman, B.; Tchervenkov, C.; Hintermann, B.; Axhasen, K.W. Observed impacts of the covid-19 first wave on travel behaviour in Switzerland based on a large GPS panel. Transp. Policy 2021, 104, 43-51. [CrossRef]

70. Przybyłowski, A.; Stelmak, S.; Suchanek, M. Mobility behaviour in view of the impact of the covid-19 pandemic-public transport users in Gdańsk case study. Sustainability 2021, 13, 364. [CrossRef]

71. Scorrano, M.; Danielis, R. Active mobility in an Italian city: Mode choice determinants and attitudies before and during the covid-19 emergency. Res. Transp. Econ. 2021, 86, 1-17. [CrossRef]

72. Aloi, A.; Alonso, B.; Benavente, J.; Cordera, R.; Echániz, E.; González, F.; Ladisa, C.; Lezama-Romanelli, R.; Lopez-Parra, A.; Mazzei, V.; et al. Effects of the COVID-19 lockdown on urban mobility: Empirical evidence from the city of Santander (Spain). Sustainability 2020, 12, 3870. [CrossRef]

73. Badii, C.; Bellini, P.; Bilotta, S.; Bologna, D.; Cenni, D.; Difino, A.; Palesi, A.I.; Mitolo, N.; Nesi, P.; Pantaleo, G.; et al. Impact on Mobility and Environmental Data of COVID-19 Lockdown on Florence Area (a DISIT Lab Data Report for COVID-19. on Mobility and Environment Focus). Available online: https:/ /arxiv.org/ftp/arxiv/papers/2005/2005.05044.pdf (accessed on 1 May 2021).

74. Konig, A.; Dressler, A. A mixed-methods analysis of mobility behavior changes in the covid-19 era in a rural case study. Eur. Transp. Res. Rev. 2021, 13, 1-13. [CrossRef] 